\title{
Chemoenzymatic Synthesis and Fluorescent Visualization of Cell-Surface Selectin-Bound Sialyl Lewis $X$ Derivatives
}

\author{
Valentin Wittmann, Arun K. Datta, Kathryn M. Koeller, and Chi-Huey Wong*[a]
}

\begin{abstract}
Sialyl Lewis $\mathrm{x}\left(\mathrm{sLe}^{\mathrm{x}}\right)$ derivatives conjugated to readily visualized molecular labels are useful chemical probes to study selectin-carbohydrate interactions. Localization of the selectins on the surface of leukocytes and activated endothelial cells can be detected through fluorescence of bound selectin ligands. Herein we present a short chemoenzymatic synthesis of a fluorescently labeled bivalent $\mathrm{sLe}^{\mathrm{x}}$ conjugate. The use of an amino-substituted monovalent $\mathrm{sLe}^{\mathrm{x}}$ to obtain fluorescent- and biotin-labeled $\mathrm{sLe}^{\mathrm{x}}$ derivatives is also described. The cell-staining utility of the fluorescent $\mathrm{sLe}^{\mathrm{x}}$ conjugates is demonstrated for a HUVEC cell line expressing E-selectin and for CHO-K1 cells expressing either L- or E-selectin.
\end{abstract}

Keywords: chemoenzymatic synthesis - oligosaccharides • regioselective glycosylation $\cdot$ selectin $\cdot$ sialyl Lewis $\mathrm{x}$

\section{Introduction}

Leukocyte adhesion to the vascular endothelium is a defining event in the inflammatory response. In the initial stages of this multistep process, leukocytes transiently tether and roll on the endothelial layer through adhesive interactions between the selectins and their carbohydrate ligands. ${ }^{[1]}$ The tetrasaccharides sialyl Lewis $\mathrm{x}\left(\mathrm{sLe}^{\mathrm{x}}\right),{ }^{[2]}$ sialyl Lewis a $\left(\mathrm{sLe}^{\mathrm{a}}\right),{ }^{[3]}$ and sulfated derivatives thereof ${ }^{[4]}$ have been identified as minimal carbohydrate epitopes recognized by selectins. Studies involving bi-,$^{[5-8,18]}$ tri- ${ }^{[7,9,10]}$ tetra- ${ }^{[11]}$ and polyvalent ${ }^{[12-17]} \mathrm{sLe}^{\mathrm{x}}$ derivatives have suggested that the selectin-ligand interaction may be multivalent in nature.

Bivalent $\mathrm{sLe}^{\mathrm{x}}$ derivative $\mathbf{1}$, previously reported by this laboratory, inhibits binding of HL-60 cells to immobilized E-selectin five times more efficiently than sLe $^{\mathrm{x}}$ itself. $^{[6 a, b]}$ Fluorescent derivatives of $\mathbf{1}$ therefore are of interest as cellstaining reagents ${ }^{[19]}$ and as tools in the development of a fluorescence-based ${ }^{[20]}$ E-selectin binding assay. ${ }^{[21]}$

As such, $N$-glycoconjugate $\mathbf{2}$ was selected as a primary synthetic target in this study. The $\beta$-alanine spacer at the carbohydrate reducing terminus facilitated the incorporation of molecular probes at a position unlikely to interfere with the selectin - ligand interaction. The strategy for the synthesis of 2 consisted of three stages: 1) chemical synthesis of trisacchar-

[a] Prof. Dr. C.-H. Wong, Dr. V. Wittmann,

Dr. A. K. Datta, K. M. Koeller

Department of Chemistry and The Skaggs Institute

for Chemical Biology

The Scripps Research Institute, 10550 North Torrey Pines Road

La Jolla, CA 92037 (USA)

Fax: (+1)858-784-2409

E-mail: wong@scripps.edu

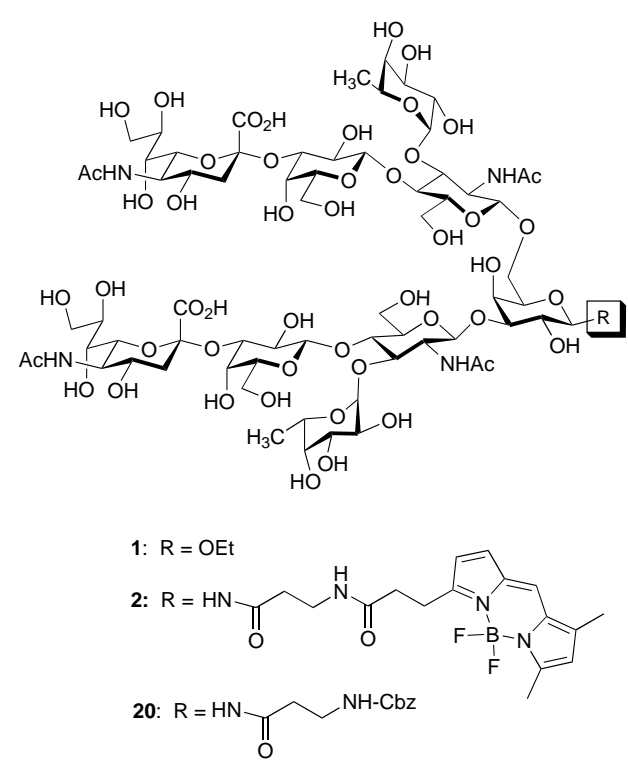

ide- $\beta$-alanine conjugate $\mathbf{1 7}, 2)$ tandem enzymatic introduction of six peripheral carbohydrates, and 3) attachment of the fluorescent label through amide coupling.

Chemoenzymatic synthesis of monomeric $\mathrm{sLe}^{\mathrm{x}}$ derivative 22 has been previously reported by this laboratory. ${ }^{[18]}$ Monomeric labeled $\mathrm{sLe}^{\mathrm{x}}$ derivatives were readily obtained through conjugation of $\mathbf{2 2}$ to molecular probes containing activated esters.

The utility of labeled sLe $^{\mathrm{x}}$-derivatives as cell-staining reagents was demonstrated for human umbilical vein endothelial cells (HUVEC) expressing E-selectin or chinese hamster ovary $(\mathrm{CHO})$ cells expressing either L- or E-selectin. 
The synthetic sLe $^{\mathrm{x}}$ conjugates were shown to bind specifically to each selectin, in a manner similar to that of anti-selectin monoclonal antibodies (mAb).

\section{Results and Discussion}

Synthetic route to divalent 2: The structure GlcNAc $\beta 1,3(\mathrm{Glc}-$ $\mathrm{NAc} \beta 1,6) \mathrm{Gal} \beta \mathrm{OR}$ represents the branch point of the I blood group antigen and the core structure of bivalent $\mathrm{sLe}^{\mathrm{x}}$ derivative 2. The preparation of $N$-glycosides of this core structure has not been previously reported. The application of glycosyl azides in the synthesis of $\mathrm{N}$-glycoconjugates is well established, ${ }^{[22]}$ and this strategy was therefore chosen here. Specifically, Kunz et al. have utilized sLe ${ }^{\mathrm{x}}$ glycosyl azides in the formation of multivalent $\mathrm{SLe}^{\mathrm{x}}$ conjugates. ${ }^{[9,10]}$ As follows, the main task in the synthesis of fluorescent conjugate 2 was to develop an efficient route to 3,6-diglycosylated galactosyl azides.

Synthesis of trisaccharide azide 12: In order to circumvent extensive protecting group manipulations, the goal was to synthesize $\mathbf{1 2}$ following the concept of minimal protection and regioselective glycosylation. ${ }^{[23]}$ The initial approach ${ }^{[24]}$ was based on 3,4- $O$-isopropylidene derivative $\mathbf{5}$ as a substrate for preferred glycosylation at the primary $6-\mathrm{OH}$ group. Thus, trisaccharide 12 was available in eight steps from penta- $O$ acetyl- $\beta$-D-galactopyranose (3) (Schemes 1 and 2). Treatment

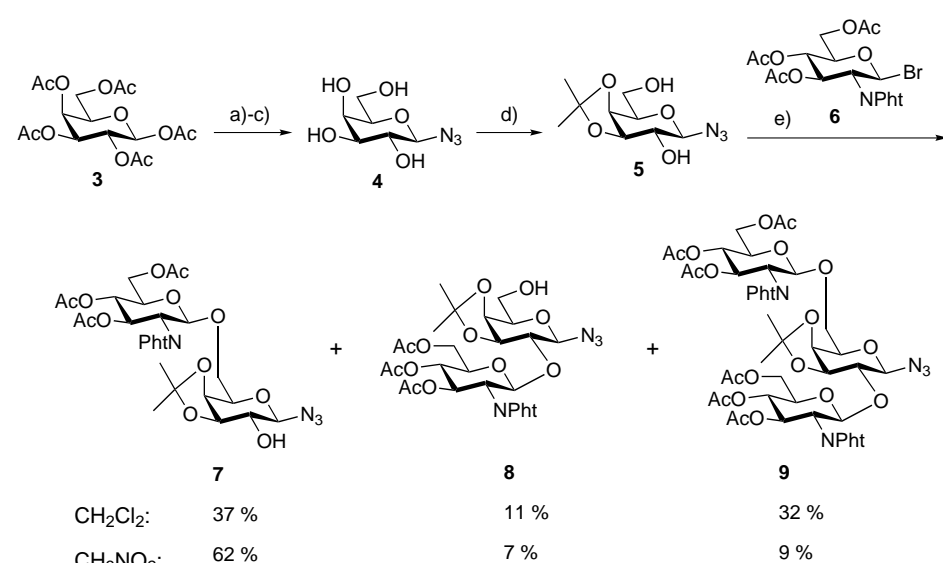

Scheme 1. a) $\mathrm{HBr}, \mathrm{HOAc}$, b) $\mathrm{NaN}_{3}, \mathrm{Bu}_{4} \mathrm{NHSO}_{4}$, EtOAc/NaHCO 3 soln; c) $\mathrm{NaOMe}, \mathrm{MeOH}, 92 \%$ (three steps); d) dimethoxypropane, $p$-TsOH, DMF; then $\mathrm{Et}_{3} \mathrm{HN}^{+} \mathrm{TsO}^{-}, \mathrm{MeOH}, \mathrm{H}_{2} \mathrm{O}$, reflux $3 \mathrm{~h}, 86 \%$; e) 6 (1.2 equiv), AgOTf, collidine, $-20^{\circ} \mathrm{C}$.

of known galactosyl azide $4^{[25]}$ with dimethoxypropane gave 3,4- $O$-isopropylidene derivative $\mathbf{5}$ in $86 \%$ yield after cleavage ${ }^{[26]}$ of the mixed acetal at the 6-hydroxyl. Small amounts of the 4,6-isomer $(4 \%)$ and the 2,3:4,6-di- $O$-isopropylidene compound ( $2 \%$ ) were also isolated from the reaction mixture. Diol acceptor 5 was then glycosylated with donor 6. ${ }^{[27]}$ Unexpectedly, when dichloromethane was employed as the solvent, only $37 \%$ of the desired $(1,6)$-linked disaccharide 7 was formed. The remainder of the reaction products were undesired regioisomer $8(11 \%)$ and trisaccharide 9 (32\%, yields based on azide 5). In nitromethane, however, the regioselectivity was acceptable, yielding $62 \%$ of $7,7 \%$ of $\mathbf{8}$, and $9 \%$ of $9 .{ }^{[28]}$ The position of the newly formed glycosidic bond in 7 was unambiguously deduced from the coupling pattern in the ${ }^{1} \mathrm{H}$ NMR spectrum of $\mathbf{7}^{\left[{ }^{[29]}\right.}$ Acetylation of $\mathbf{7}$ and removal of the isopropylidene group gave diol 11 (Scheme 2). In contrast to acceptor $\mathbf{5}$, glycosylation of the $2-O$-acetylated
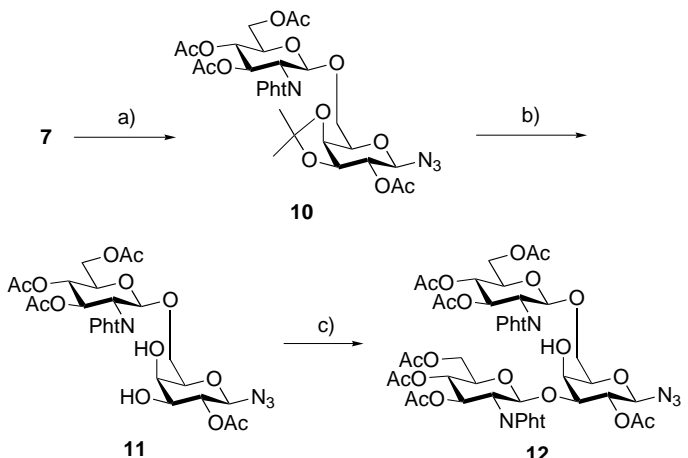

Scheme 2. a) $\mathrm{Ac}_{2} \mathrm{O}$, pyridine, $97 \%$; b) $80 \%$ HOAc, $74 \%$; c) 6 ( 1.5 equiv), AgOTf, collidine, $\mathrm{CH}_{2} \mathrm{Cl}_{2},-20^{\circ} \mathrm{C}, 84 \%$.

acceptor $\mathbf{1 1}$ proceeded with remarkable regioselectivity at the equatorial 3-position and furnished $\mathbf{1 2}$ in $84 \%$ yield. ${ }^{[30]}$ In this reaction, dichloromethane was the solvent of choice, since the use of nitromethane under otherwise identical conditions resulted in incomplete reaction. However, in both cases, glycosylation at the 4-position of the 3,4-diol could not be detected. Since it is also possible to selectively glycosylate 4,6diols in galactopyranosides at the 6-position, ${ }^{[6 b, 23 c, e, f]}$ it was expected that the 2-O-acetylated 3,4,6-triol $\mathbf{1 4}$ would be a promising glycosyl acceptor for a simultaneous introduction of two glucosamine residues in the 3- and 6-positions of the galactose ring. ${ }^{[31]}$

In an alternative synthetic strategy, 14 was efficiently obtained by making use of a 1,2-orthoester (Scheme 3).

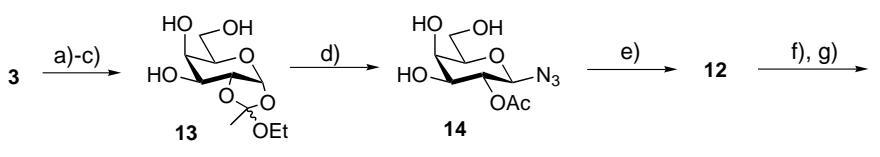

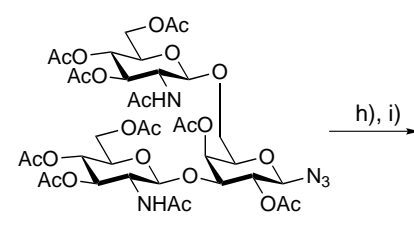

15

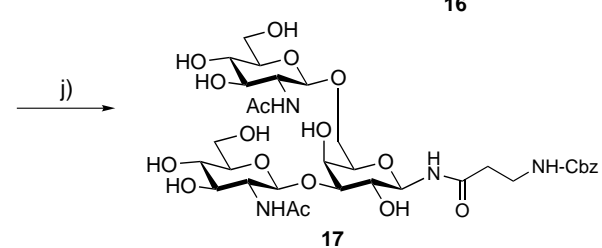

Scheme 3. a) $\mathrm{HBr}$, HOAc; b) $\mathrm{Bu}_{4} \mathrm{NBr}$, EtOH, collidine; c) $\mathrm{NaOMe}$, $\mathrm{MeOH}, 87 \%$ (three steps); d) TMS-N $\mathrm{N}_{3}$ (10 equiv), THF, rt to reflux, then $80 \%$ HOAc, $90 \%$; e) 6 (2.5 equiv), AgOTf, collidine, $\mathrm{CH}_{2} \mathrm{Cl}_{2},-30{ }^{\circ} \mathrm{C}$, $70 \%$; f) ethylene diamine; g) $\mathrm{Ac}_{2} \mathrm{O}$, pyridine, $90 \%$ (two steps); h) $\mathrm{H}_{2} / \mathrm{Pd}-\mathrm{C}$; i) Cbz- $\beta$-Ala-OH, HBTU, HOBt, $i \mathrm{Pr}_{2} \mathrm{NEt}, 67 \%$ (two steps); j) NaOMe, $\mathrm{MeOH}, 86 \%$. 
Bromination $^{[32]}$ of pentaacetate $\mathbf{3}$, followed by cyclization ${ }^{[33]}$ and deprotection gave orthoester $\mathbf{1 3}^{[34]}$ as a mixture of epimers (endo/exo 83:17). The orthoester functionality served as a means to both distinguish the 2-OH group from the remaining hydroxyls and activate the anomeric carbon. Thus, treatment of triol $\mathbf{1 3}$ with trimethylsilyl azide ${ }^{[35]}$ provided triol $\mathbf{1 4}$ in a single step in $90 \%$ yield. In this case, acidic work-up was necessary to remove TMS ethers generated in situ. Silver triflate promoted diglycosylation of $\mathbf{1 4}$ with donor $\mathbf{6}$ in dichloromethane resulted in the formation of trisaccharide $\mathbf{1 2}$ in a yield of $70 \%$. Small amounts of intermediate $\mathbf{1 1}$ formed in the reaction were easily removed by flash chromatography. With this approach, trisaccharide $\mathbf{1 2}$ was accessible from pentaacetate $\mathbf{3}$ in only five steps and high overall yield.

Synthesis of trisaccharide- $\boldsymbol{\beta}$-alanine conjugate 17: Deprotection of 12 with ethylene diamine, ${ }^{[36]}$ followed by treatment with acetic anhydride, furnished peracetylated trisaccharide $\mathbf{1 5}$ in $90 \%$ yield. Hydrazine hydrate could not be used to remove the phthaloyl groups as a result of a side reaction of the anomeric azido function. The azido function was smoothly reduced hydrogenolytically on palladium black, and the resulting glycosyl amine was coupled to Cbz-protected $\beta$ alanine with $\mathrm{HBTU}^{[37]}$ as coupling reagent. $O$-Deacetylation utilizing Zemplen conditions gave glycoconjugate 17, which was used as a primer in subsequent glycosyltransferasecatalyzed $^{[38]}$ glycosylations.

Enzymatic glycosylations and attachment of the fluorophor: Treatment of primer 17 with $\beta$-1,4-galactosyltransferase $(\beta$ $1,4-\mathrm{GalT}$ ) and 2.6 equivalents of UDP-Gal gave pentasaccharide 18 in quantitative yield (Scheme 4). Similarly, two sialic acid residues were introduced with $\alpha$-2,3-sialyltransferase $(\alpha-2,3-$ SiaT) to give heptasaccharide 19 (92\% yield). Subsequent addition of two fucose residues employing $\alpha-1,3-$ fucosyltransferase $\mathrm{V}(\alpha-1,3-\mathrm{FucT} \mathrm{V})$ then afforded nonasaccharide 20 (see above, $85 \%$ yield). Alkaline phosphatase (AP) was added to all three glycosylation reactions in order to prevent product inhibition ${ }^{[39]}$ by UDP, CMP, and GDP, respectively, and to facilitate product isolation from these nucleotides by size-exclusion chromatography. Notably, 17, 18, and 19 were accepted as substrates by the transferases despite the presence of the unnatural $\mathrm{Cbz}-\beta$-alanine group at the reducing terminus. Finally, Cbz-protected glycoconjugate 20 was deprotected hydrogenolytically and reacted with BODIPY-succinimidyl ester 21, leading to fluorescently labeled nonasaccharide- $\beta$-alanine conjugate $\mathbf{2}$ in $89 \%$ yield.

In summary, following the protecting group strategy presented in Schemes 3 and 4, the synthesis of $\mathbf{2}$ was accomplished in only 15 steps from commercially available $\mathbf{3}$.

Synthesis of fluorescent- and biotin-labeled derivatives 23 and 25: Recently, the synthesis of amino-substituted sLe ${ }^{\mathrm{x}}$ derivative $\mathbf{2 2}$ was described. Compound $\mathbf{2 2}$ was employed in the preparation of $\mathrm{sLe}^{\mathrm{x}}$ dimers with oligoethylene glycol based spacers of varying chain length. ${ }^{[18]}$ As shown in Scheme 5, 22 was also coupled to the succinimidyl esters $\mathbf{2 1}$ and $\mathbf{2 4}$ to produce fluorescent BODIPY-labeled sLe ${ }^{\mathrm{x}}$ derivative $\mathbf{2 3}$ and biotinylated sLe $^{\mathrm{x}}$ derivative $\mathbf{2 5}$ in $83 \%$ and $65 \%$ yields, respectively. Thus, labeled monovalent $\mathrm{sLe}^{\mathrm{x}}$ derivatives were also easily accessible by short chemoenzymatic routes.

Application of fluorescent sLe $^{\mathrm{x}}$ derivatives as cell-staining reagents: The cell-staining utility of the fluorescently labeled $\mathrm{sLe}^{\mathrm{x}}$ conjugates was then demonstrated. First, stable CHO-K1 cell lines expressing either L-selectin or E-selectin were generated. Full length L- ${ }^{[44]}$ and E-selectin ${ }^{[45]}$ were amplified with primers based on the published sequences by using the reverse transcriptase (RT) product as the template. These were subcloned in pcDNA.3, a mammalian expression vector with CMV promoter, and Neo gene as the selectable marker. In CHO-K1, the selectins were expressed on the cell surface with normal transmembrane topology. After transfection, cells incorporating the expression vector were selected by G418 resistance. For further selection, the individual colonies were grown in duplicate plates. One of the plates was used for

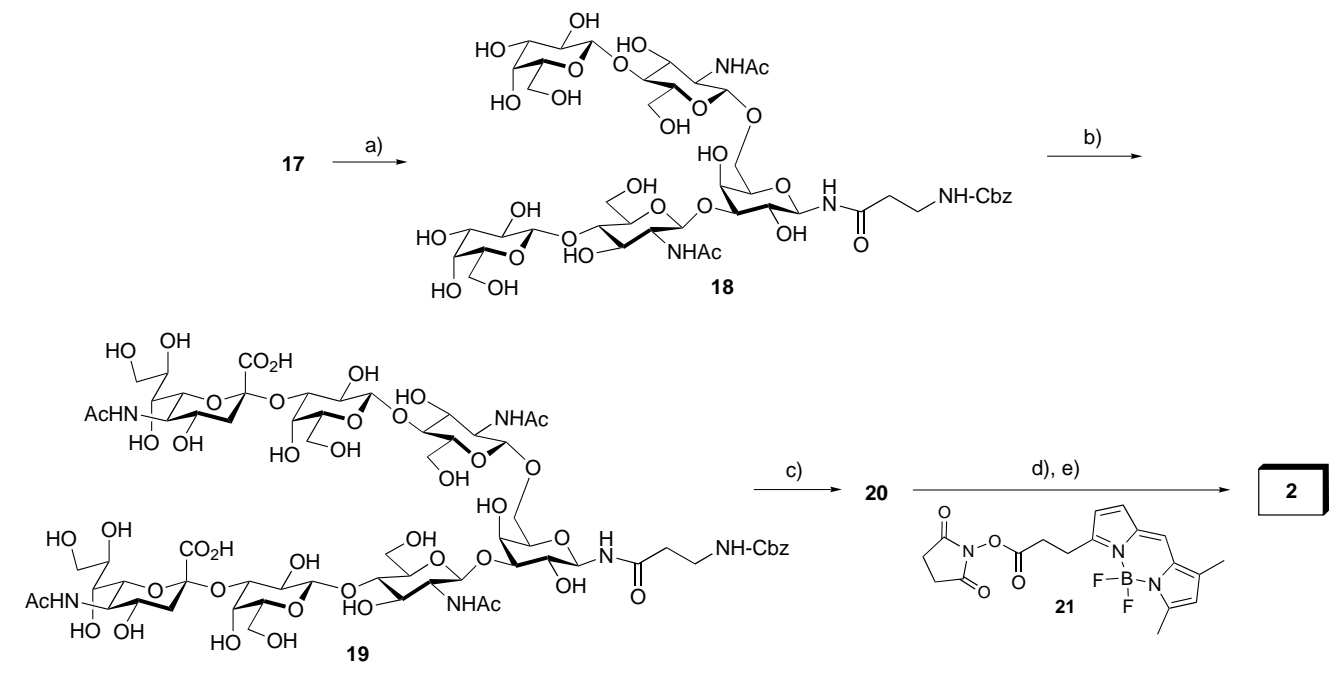

Scheme 4. a) UDP-Gal (2.6 equiv), $\beta$-1,4-GalT, AP, quant.; b) CMP-NeuAc (3.6 equiv), $\alpha$-2,3-SiaT, AP, $92 \%$; c) GDP-Fuc (3 equiv), $\alpha-1,3-$ FucT V, AP, $85 \%$; d) $\mathrm{H}_{2} / \mathrm{Pd}-\mathrm{C}$; e) 21, $\mathrm{Et}_{3} \mathrm{~N}, \mathrm{DMF}, \mathrm{H}_{2} \mathrm{O}, 89 \%$ (two steps). 

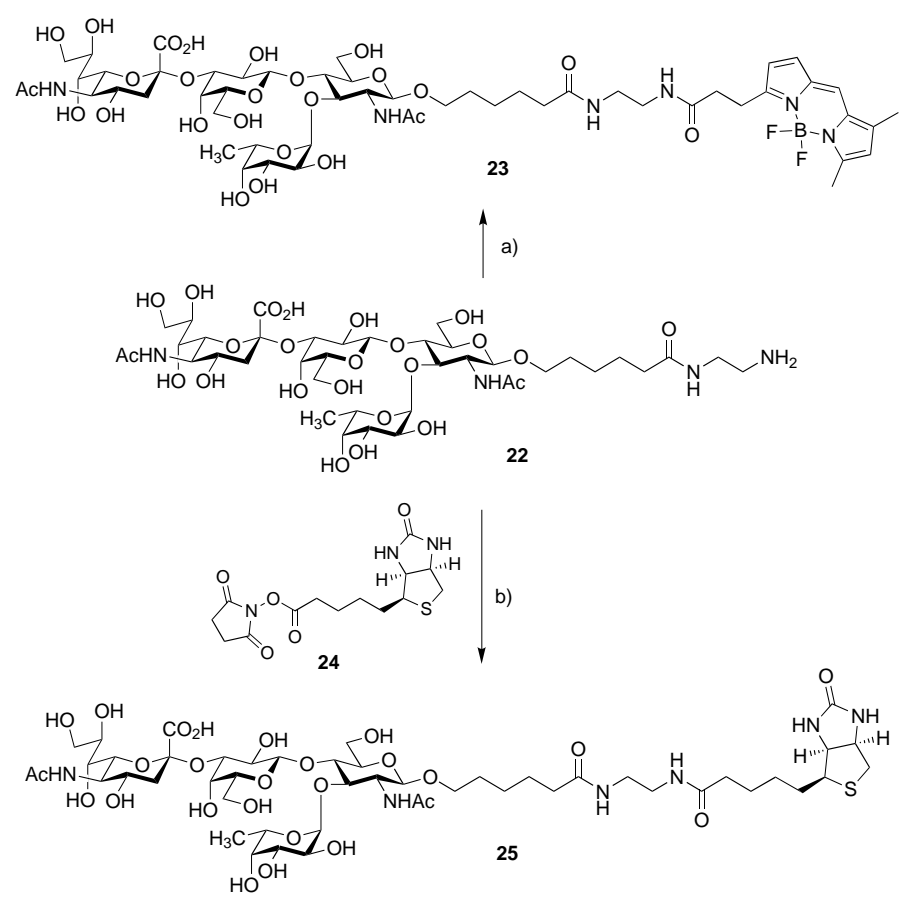

Scheme 5. a) 21, $\mathrm{Et}_{3} \mathrm{~N}, \mathrm{DMF}, 83 \%$; b) 24, $\mathrm{Et}_{3} \mathrm{~N}, \mathrm{DMF}, 65 \%$.

ELISA, employing monoclonal antibodies for either L-selectin (mAb CD62L) or E-selectin (mAb CD62E), respectively. In the ELISA assay, individual CHO-K1 cell lines expressing L- or E-selectin were identified. The cell lines with maximal $\mathrm{OD}_{450}$ were used for fluorescence activated cell sorting (FACS) analysis, and the top $0.1 \%$ of cells showing expression were collected (Figure 1). These cells were grown in MEM (minimum essential medium) medium containing 5\% fetal calf serum, G418 (100 $\left.\mu \mathrm{g} \mathrm{mL}^{-1}\right)$, and $1 \% \mathrm{~L}$-glutamine, and finally selected by limited dilution method.

In another set of experiments, HUVEC cells were stimulated to produce cell-surface E-selectin by treatment with lipopolysaccharide (LPS) and/or interferon- $1 \beta$ (IFN-1 $\beta$ ) following previously published procedures. ${ }^{[2 \mathrm{~d}, 12]}$ Expression of E-selectin on the cell surface was verified by staining the activated cells with mAb CD62E, as described above. After the cells were washed, they were fixed and visualized under a fluorescence microscope. The antibody was detected at $570 \mathrm{~nm}$ by using TRITC-conjugated anti-mouse IgG.

After the expression of the cell-surface E-selectin was established, the cells were incubated with the BODIPYlabeled mono- and divalent $\mathrm{sLe}^{\mathrm{x}}$ conjugates. The cells were washed again, fixed, and visualized under a fluorescence microscope. BODIPY-labeled conjugates were detected by intrinsic fluorescence at $508 \mathrm{~nm}$.

Figure 2 shows the cell-staining experiments performed with the CHO-K1 cells expressing E-selectin, while Figure 3 shows similar experiments conducted with L-selectin. The
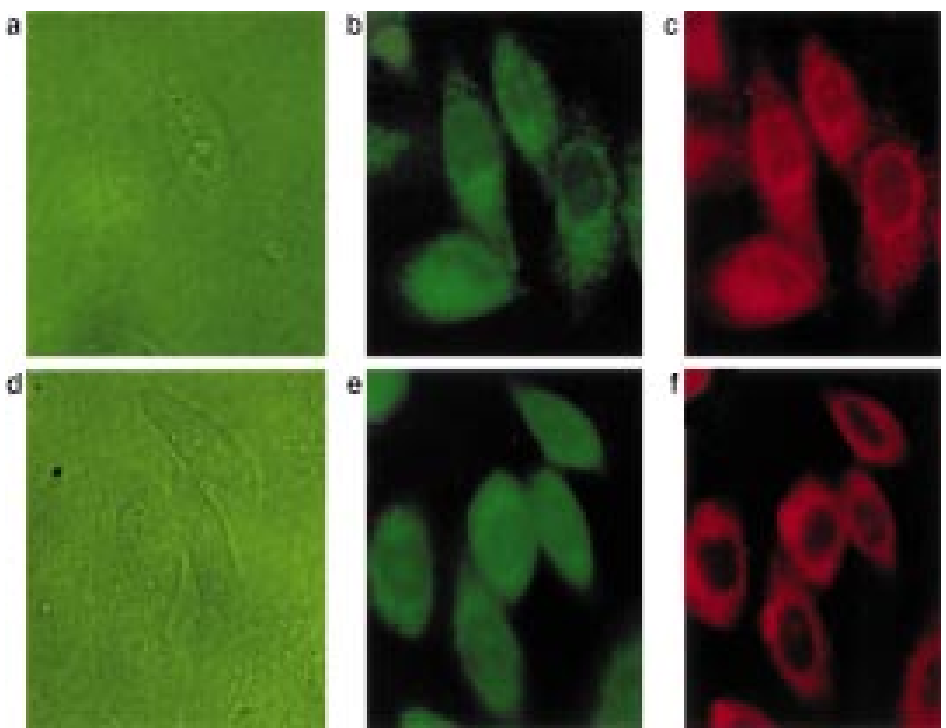

Figure 2. CHO-K1 cells expressing E-selectin: a) under transmitted light; b) stained with BODIPY-labeled $\mathrm{sLe}^{\mathrm{x}}$ monomer 23 ; c) cell stained with CD62E mAb followed by TRITC-conjugated anti-mouse IgG; d) under transmitted light; e) stained with BODIPY-labeled $\mathrm{sLe}^{\mathrm{x}}$ dimer 2 ; f) stained with CD62E mAb followed by TRITC-conjugated anti-mouse IgG. CHOK1 cells negative for E-selectin expression did not exhibit staining with 2 , 23, or CD62E mAb (data not shown).

staining of HUVEC cells expressing E-selectin is shown in Figure 4. At the present levels of selectin expression, the cellstaining pattern observed is similar for the $\mathrm{mAb}$ and the $\mathrm{sLe}^{\mathrm{x}}$ derivatives for all cell lines investigated. Thus, the usefulness of the labeled $\mathrm{sLe}^{\mathrm{x}}$ derivatives in localizing E- and L-selectin on various cell surfaces has been established by these experiments. Though E-selectin expression has been visualized with fluorescent $\mathrm{sLe}^{\mathrm{x}}$-based ligands previously, we are unaware of other reports of this nature involving the detection of L-selectin.

In the binding analysis of carbohydrate ligands for the selectins, it is necessary to verify that mimetic structures have access to the appropriate car-
Figure 1. FACS analysis of the TRITC-stained CHO-K1 stable cell lines: a) cells expressing E-selectin were stained with CD62E mAb followed by TRITC-conjugated anti-mouse IgG; b) cells expressing L-selectin were stained with CD62L mAb followed by TRITC-conjugated anti-mouse IgG. $0.1 \%$ of the maximally intense cells were sorted out.
B

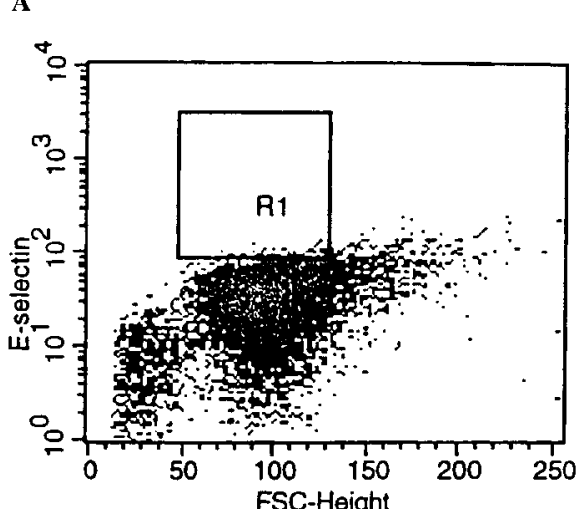

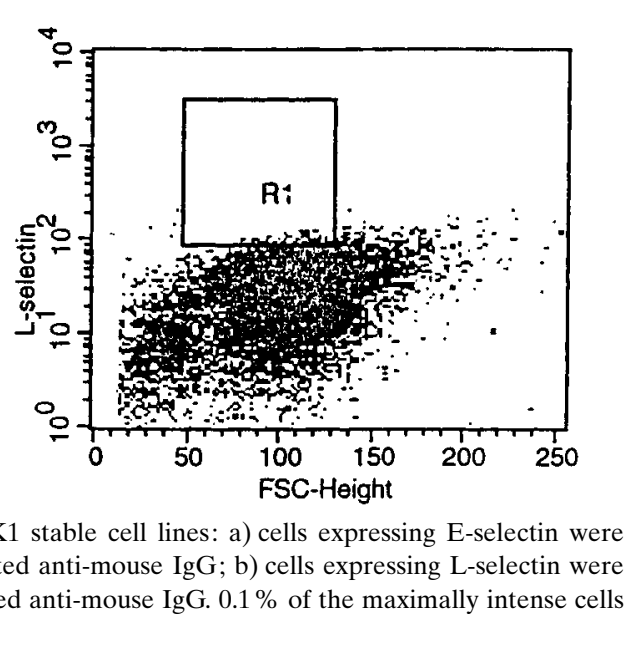



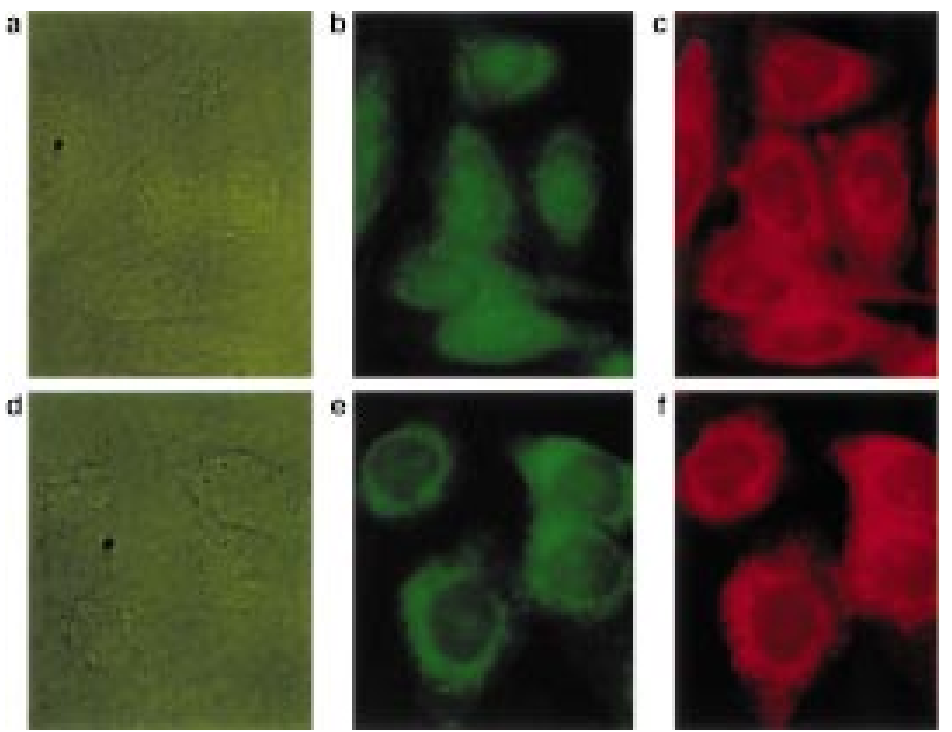

Figure 3. CHO-K1 cells expressing L-selectin: a) under transmitted light; b) stained with BODIPY-labeled $\mathrm{sLe}^{\mathrm{x}}$ monomer 23 ; c) cell stained with CD62L mAb followed by TRITC-conjugated anti-mouse IgG; d) under transmitted light: e) stained with BODIPY-labeled $\mathrm{sLe}^{\mathrm{x}}$ dimer 2 ; f) stained with CD62L mAb followed by TRITC-conjugated anti-mouse IgG. CHO$\mathrm{K} 1$ cells negative for L-selectin expression did not exhibit staining with $\mathbf{2}$, 23, or CD62L mAb (data not shown).
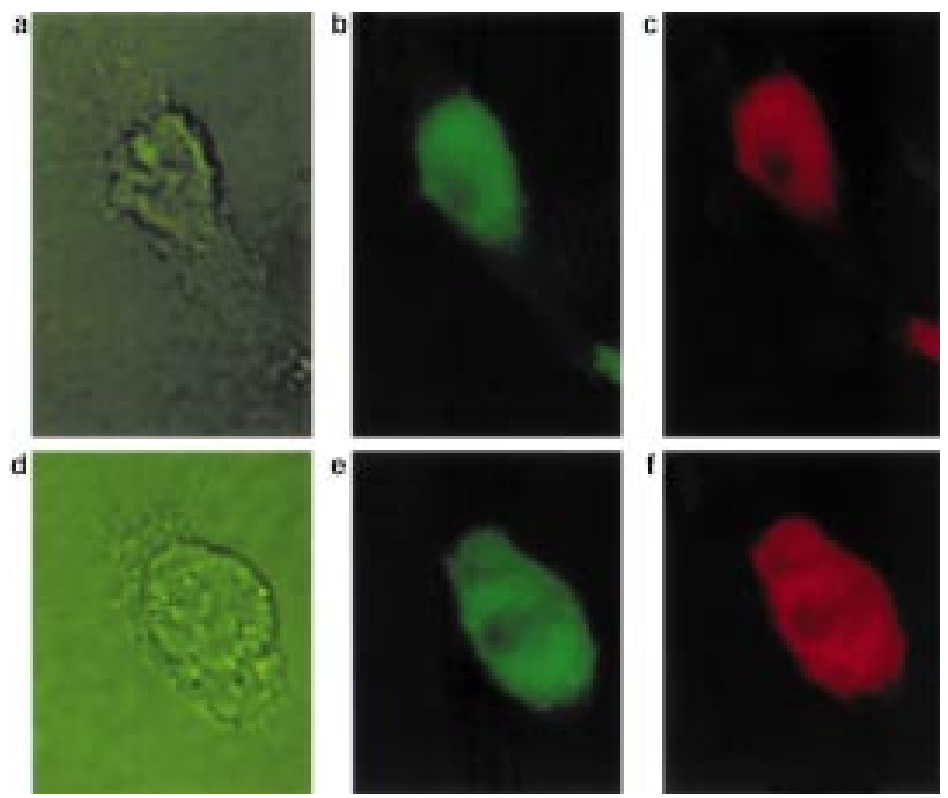

Figure 4. HUVEC cells expressing cell surface E-selectin: a) a cell under transmitted light; b) cell stained with BODIPY-labeled sLe ${ }^{\mathrm{x}}$ monomer $\mathbf{2 3}$; c) cell stained with $\mathrm{CD} 62 \mathrm{E} \mathrm{mAb}$ followed by TRITC-conjugated anti mouse IgG; d) another cell under transmitted light; e) cell stained with BODIPY-labeled sLe ${ }^{\mathrm{x}}$ dimer 2 ; f) cell stained with CD62E mAb followed by TRITC-conjugated anti mouse IgG. HUVEC cells negative for E-selectin expression did not exhibit staining with 2, 23, or CD62E mAb (data not shown).

bohydrate binding site. This is the advantage of using small molecular $\mathrm{sLe}^{\mathrm{x}}$ conjugates rather than anti-selectin $\mathrm{mAbs}$ in this type of experiment. Selectins with accessible carbohydrate recognition domains on the cell surface can be assessed directly utilizing the described $\mathrm{sLe}^{\mathrm{x}}$ constructs.

\section{Conclusion}

A short and efficient synthesis of fluorescently labeled bivalent $\mathrm{sLe}^{\mathrm{x}}-\beta$-alanine conjugate $\mathbf{2}$ has been demonstrated with a combined chemical and enzymatic approach. The key features of the synthetic strategy were the transformation of unprotected orthoester $\mathbf{1 3}$ into selectively protected galactosyl azide 14, and subsequent regioselective diglycosylation to give trisaccharide $\mathbf{1 2}$. The $\beta$-alanine spacer introduced subsequently facilitated the incorporation of molecular probes, and also allows the possible formation of numerous neoglycoconjugates. ${ }^{[40]}$ Glycosyltransferase-catalyzed elongation of the carbohydrate branches proceeded in excellent yields, despite the presence of the nonnatural Cbz- $\beta$-alanine group. Commencing with galactose pentaacetate $\mathbf{3}$, fluorescently labeled conjugate $\mathbf{2}$ was obtained in only 15 steps and an overall yield of $20 \%$. To demonstrate the utility of labeled $\mathrm{sLe}^{\mathrm{x}}$-derivatives as tools in localizing cell-surface selectins, the $\mathrm{sLe}^{\mathrm{x}}$ conjugates were subjected to a cell-staining assay. Similar cell-staining patterns of the sLe $^{x}$ derivatives and anti-selectin mAbs on the surface of activated HUVEC cells and CHO-K1 cells was observed. As such, the usefulness of small molecular $\mathrm{sLe}^{\mathrm{x}}$-derivatives as cell-staining reagents has been established. Furthermore, these results may lead to the development of a fluorescence-based selectin binding assay in the near future.

\section{Experimental Section}

General methods: $\beta$-D-Galactopyranosyl azide (4), ${ }^{[25,32,42]}$ 3,4,6-tri- $O$ acetyl-2-deoxy-2-phthalimido- $\beta$-D-glucopyranosyl bromide (6), ${ }^{[27]} 1,2-O$ $\left((1 R S)\right.$-1-ethoxyethylidene)- $\beta$-D-galactopyranose $(\mathbf{1 3}),{ }^{[32-34]}$ and monoammonium GDP-Fuc ${ }^{[43]}$ were prepared according to published procedures. 1,2,3,4,6-Penta- $O$-acetyl- $\beta$-D-galactopyranose (3), $N$-hydroxysuccinimidobiotin (24), UDP-Gal, $\beta-1,4-G a l T$, and alkaline phosphatase (type VII-N, from bovine intestinal mucosa, P-2276) were purchased from Sigma (St. Louis, MO). CMP-NeuAc (sodium salt) was purchased from Calbiochem (San Diego, CA). 4,4-Difluoro-5,7-dimethyl-4-bora-[3a,4a]-diaza-s-indacene-3-propionic acid succinimidyl ester (21) (BODIPY FL, SE) was purchased from Molecular Probes (Eugene, OR). $\alpha$-2,3-SiaT $\left(3 \mathrm{U} \mathrm{mL}^{-1}\right)$ and $\alpha$-1,3-FucT V (2.16 $\left.\mathrm{UmL}^{-1}\right)$ were a kind donation from Cytel (San Diego, CA). Flash chromatography (FC) was performed on Mallinckrodt silica gel 60 (230-400 mesh). Analytical thin-layer chromatography was performed by using silica gel $60 \mathrm{~F}_{254}$ precoated glass plates from Merck (Darmstadt, Germany); compound spots were visualized by quenching of fluorescence and/or by charring after treatment with cerium molybdophoshate. Size-exclusion chromatography was performed on Bio-Gel P-2 Gel, fine and Bio-Gel P-4 Gel, fine (Bio-Rad Laboratories, Hercules, CA). NMR spectra were recorded on Bruker AM-250, AMX-400 or AMX-500 spectrometers. ${ }^{1} \mathrm{H}$ NMR chemical shifts are referenced to residual protic solvent $\left(\mathrm{CDCl}_{3} \delta_{\mathrm{H}}=7.26, \mathrm{D}_{2} \mathrm{O} \delta_{\mathrm{H}}=4.80,\left[\mathrm{D}_{6}\right] \mathrm{DMSO} \delta_{\mathrm{H}}=2.50\right)$ or internal standard TMS $\left(\delta_{\mathrm{H}}=0.00\right) .{ }^{13} \mathrm{C}$ chemical shifts are referenced to the solvent signal $\left(\mathrm{CDCl}_{3} \delta_{\mathrm{C}}=77.0,\left[\mathrm{D}_{6}\right] \mathrm{DMSO} \delta_{\mathrm{C}}=39.5\right)$ or to $\left[\mathrm{D}_{6}\right] \mathrm{DMSO}\left(\delta_{\mathrm{C}}=39.5\right)$ as external standard. High resolution mass spectra (HR-MS) were recorded by using fast atom bombardment (FAB) method in a $m$-nitrobenzyl alcohol matrix doped with $\mathrm{NaI}$ or CsI.

3,4-O-Isopropylidene- $\beta$-D-galactopyranosyl azide (5), 4,6- $O$-isopropylidene- $\boldsymbol{\beta}$-D-galactopyranosyl azide, and $2,3: 4,6$-di- $O$-isopropylidene- $\beta$-D-galactopyranosyl azide: $\beta$-D-Galactopyranosyl azide (4) $(0.97 \mathrm{~g}, 4.73 \mathrm{mmol})$ was dissolved in DMF $(10 \mathrm{~mL})$ and 2,2-dimethoxypropane $(20 \mathrm{~mL})$ and heated to $65^{\circ} \mathrm{C}$. $p$-Toluenesulfonic acid $(90 \mathrm{mg}, 0.473 \mathrm{mmol})$ was added and the solution was stirred at $65^{\circ} \mathrm{C}$ for $5 \mathrm{~h}$. After the solution was cooled down to $\mathrm{rt}, \mathrm{Et}_{3} \mathrm{~N}(660 \mu \mathrm{L}, 4.73 \mathrm{mmol})$ was added and the mixture was stirred for $15 \mathrm{~min}$. The mixture was concentrated to dryness and toluene was evaporated twice from the residue in order to remove traces of $\mathrm{Et}_{3} \mathrm{~N}$. The 
residue was dissolved in $\mathrm{MeOH} / \mathrm{H}_{2} \mathrm{O}(10: 1)(40 \mathrm{~mL})$ and boiled for $30 \mathrm{~min}$ until TLC (hexane/ethyl acetate 1:2) showed the complete disappearance of the intermediate product 6-O-(2-methoxy-2-propyl)-3,4-O-isopropylidene- $\beta$-D-galactopyranosyl azide $\left(R_{\mathrm{f}}=0.45\right)$. The solution was concentrated and coevaporated twice with toluene. FC ( $80 \mathrm{~g}$ silica, hexane/ethyl acetate $1: 2$, then ethyl acetate and finally ethyl acetate/methanol 9:1) gave $2,3: 4,6$-di- $O$-isopropylidene- $\beta$-D-galactopyranosyl azide ( $20 \mathrm{mg}, 2 \%$ ), then $5(1.00 \mathrm{~g}, 86 \%)$ and 4,6- $O$-isopropylidene- $\beta$-D-galactopyranosyl azide (51 mg, 4\%).

Data for 5: $R_{\mathrm{f}}=0.21$ (hexane/ethyl acetate 1:2); white crystals (ethyl acetate/hexane); m.p. $113.5-114{ }^{\circ} \mathrm{C} ;{ }^{1} \mathrm{H}$ NMR (400 $\left.\mathrm{MHz} \mathrm{CDCl}_{3}\right): \delta=4.51$ $(\mathrm{d}, 1 \mathrm{H}, J=8.9 \mathrm{~Hz}, 1-\mathrm{H}), 4.22(\mathrm{dd}, 1 \mathrm{H}, J=2.1,5.5 \mathrm{~Hz}, 4-\mathrm{H}), 4.11(\mathrm{dd}, 1 \mathrm{H}$, $J=5.5,7.2 \mathrm{~Hz}, 3-\mathrm{H}), 4.04-3.96(\mathrm{~m}, 2 \mathrm{H}, 5-\mathrm{H}, 6-\mathrm{H}), 3.87\left(\mathrm{~m}, 1 \mathrm{H}, 6^{\prime}-\mathrm{H}\right), 3.50$ (ddd, $1 \mathrm{H}, J=3.2,7.2,8.9 \mathrm{~Hz}, 2-\mathrm{H}), 2.50(\mathrm{~d}, 1 \mathrm{H}, J=3.2 \mathrm{~Hz}, 2-\mathrm{OH}), 2.18(\mathrm{~m}$, $1 \mathrm{H}, 6-\mathrm{OH}), 1.53\left(\mathrm{~s}, 3 \mathrm{H}, \mathrm{CH}_{3}\right), 1.37\left(\mathrm{~s}, 3 \mathrm{H}, \mathrm{CH}_{3}\right) ;{ }^{13} \mathrm{C} \mathrm{NMR}(100 \mathrm{MHz}$, $\left.\mathrm{CDCl}_{3}\right): \delta=110.7\left(\mathrm{CMe}_{2}\right), 89.7,78.5,75.2,73.7,73.1,62.4,28.0\left(\mathrm{CH}_{3}\right), 26.2$ $\left(\mathrm{CH}_{3}\right)$; HR-MS (pos. FAB, NBA/CsI) calcd for $\mathrm{C}_{9} \mathrm{H}_{15} \mathrm{~N}_{3} \mathrm{O}_{5} \mathrm{Cs}[M+\mathrm{Cs}]^{+}$ $m / z$ : 378.0066, found 378.0077; anal. calcd for $\mathrm{C}_{9} \mathrm{H}_{15} \mathrm{~N}_{3} \mathrm{O}_{5}$ : C 44.08, H 6.17, N 17.13; found: C 43.99, H 6.32, N 16.97 .

4,6- $\boldsymbol{O}$-Isopropylidene- $\boldsymbol{\beta}$-D-galactopyranosyl azide: $\boldsymbol{R}_{\mathrm{f}}=0.06$ (hexane/ethyl acetate 1:2); white crystals (ethyl acetate/hexane); m.p. $145-146^{\circ} \mathrm{C}$; ${ }^{1} \mathrm{H}$ NMR $\left(250 \mathrm{MHz}, \mathrm{CDCl}_{3}\right): \delta=4.53(\mathrm{~d}, 1 \mathrm{H}, J=8.0 \mathrm{~Hz}, 1-\mathrm{H}), 4.21$ (dd, $1 \mathrm{H}, J=1.1,3.3 \mathrm{~Hz}, 4-\mathrm{H}), 4.10(\mathrm{dd}, 1 \mathrm{H}, J=2.2,13.0 \mathrm{~Hz}, 6-\mathrm{H}), 3.99(\mathrm{dd}, 1 \mathrm{H}$, $\left.J=1.7,13.0 \mathrm{~Hz}, 6^{\prime}-\mathrm{H}\right), 3.69-3.57$ (m, 2 H, 2-H, 3-H), 3.48 (m, 1 H, 5-H), 2.55 (brs, 2H, 2-OH, 3-OH), $1.48\left(\mathrm{~s}, 3 \mathrm{H}, \mathrm{CH}_{3}\right), 1.47\left(\mathrm{~s}, 3 \mathrm{H}, \mathrm{CH}_{3}\right) ;{ }^{13} \mathrm{C} \mathrm{NMR}$ $\left(62.9 \mathrm{MHz}, \mathrm{CDCl}_{3}\right) \delta=99.3\left(\mathrm{CMe}_{2}\right), 90.1(\mathrm{C}-1), 72.8,71.2,68.4,67.8,62.3$, $29.0\left(\mathrm{CH}_{3}\right), 18.6\left(\mathrm{CH}_{3}\right)$; anal. calcd for $\mathrm{C}_{9} \mathrm{H}_{15} \mathrm{~N}_{3} \mathrm{O}_{5}: \mathrm{C} 44.08 ; \mathrm{H}, 6.17 ; \mathrm{N}$, 17.13; found: C 44.26; H 6.24; N, 17.00 .

2,3:4,6-Di- $\boldsymbol{O}$-isopropylidene- $\boldsymbol{\beta}$-D-galactopyranosyl azide: $\boldsymbol{R}_{\mathrm{f}}=0.49$ (hexane/ethyl acetate 1:2); syrup; ${ }^{1} \mathrm{H}$ NMR $\left(250 \mathrm{MHz}, \mathrm{CDCl}_{3}\right): \delta=4.80(\mathrm{~d}, 1 \mathrm{H}$, $J=8.6 \mathrm{~Hz}, 1-\mathrm{H}), 4.48(\mathrm{dd}, 1 \mathrm{H}, J=1.4,2.8 \mathrm{~Hz}, 4-\mathrm{H}), 4.16(\mathrm{dd}, 1 \mathrm{H}, J=2.2$, $13.1 \mathrm{~Hz}, 6-\mathrm{H}), 4.04$ (dd, $\left.1 \mathrm{H}, J=1.6,13.1 \mathrm{~Hz}, 6^{\prime}-\mathrm{H}\right), 3.91$ (dd, $1 \mathrm{H}, J=8.6$, $9.4 \mathrm{~Hz}, 2-\mathrm{H}), 3.56$ (dd, $1 \mathrm{H}, J=2.8,9.4 \mathrm{~Hz}, 3-\mathrm{H}), 3.44$ (ddd, $1 \mathrm{H}, J=1.4,1.6$, $2.2 \mathrm{~Hz}, 5-\mathrm{H}), 1.50\left(\mathrm{~s}, 6 \mathrm{H}, 2 \mathrm{CH}_{3}\right), 1.473\left(\mathrm{~s}, 3 \mathrm{H}, \mathrm{CH}_{3}\right), 1.466\left(\mathrm{~s}, 3 \mathrm{H}, \mathrm{CH}_{3}\right)$; ${ }^{13} \mathrm{C}$ NMR $\left(62.9 \mathrm{MHz}, \mathrm{CDCl}_{3}\right): \delta=111.5\left(\mathrm{CMe}_{2}\right), 98.7\left(\mathrm{CMe}_{2}\right), 89.2(\mathrm{C}-1)$, 78.4, 72.0, 69.0, 66.2, 62.7, $29.0\left(\mathrm{CH}_{3}\right), 26.5\left(\mathrm{CH}_{3}\right), 26.4\left(\mathrm{CH}_{3}\right), 18.5\left(\mathrm{CH}_{3}\right)$.

6- $O$-(3,4,6-Tri- $O$-acetyl-2-deoxy-2-phthalimido- $\beta$-D-glucopyranosyl)-3,4$O$-isopropylidene- $\beta$-D-galactopyranosyl azide (7), 2- $O$-(3,4,6-tri- $O$-acetyl2-deoxy-2-phthalimido- $\beta$-D-glucopyranosyl)-3,4- $O$-isopropylidene- $\beta$-D-galactopyranosyl azide (8), and 2,6-bis- $O$-(3,4,6-tri- $O$-acetyl-2-deoxy-2-phthalimido- $\boldsymbol{\beta}$-D-glucopyranosyl)-3,4- $\boldsymbol{O}$-isopropylidene- $\boldsymbol{\beta}$-D-galactopyranosyl

azide (9): Procedure A: A solution of $5(60 \mathrm{mg}, 0.244 \mathrm{mmol})$ and 2,4,6collidine $(43 \mu \mathrm{L}, 0.324 \mathrm{mmol})$ in nitromethane $(3.5 \mathrm{~mL})$ was mixed with powdered molecular sieves ( $4 \AA$ ) (ca. $300 \mathrm{mg}$ ) and stirred under argon for $1.5 \mathrm{~h}$ at rt. Freshly dried AgOTf $(76 \mathrm{mg}, 0.295 \mathrm{mmol})$ was added and the yellowish mixture was cooled to $-20^{\circ} \mathrm{C}$. A solution of $6(146 \mathrm{mg}$, $0.293 \mathrm{mmol})$ in nitromethane $(3.5 \mathrm{~mL})$ was added dropwise during $15 \mathrm{~min}$ to the reaction mixture. After $3 \mathrm{~h}$ at $-20^{\circ} \mathrm{C}$, the mixture was allowed to warm up slowly to rt. After a total reaction time of $8 \mathrm{~h}$, the mixture was diluted with acetonitrile, filtered through Celite, and evaporated to give a syrup (324 mg). FC (25 g silica, toluene/ethyl acetate $1: 1$, then ethyl acetate) gave 9 (24 mg, $9 \%$ based on 5), then 7 (100 mg, $62 \%), 8(11 \mathrm{mg}$, $7 \%$ ), and finally unreacted $\mathbf{5}$ (12 mg, $20 \%$ )

Procedure B: Powdered molecular sieves (4 Å) (ca. $150 \mathrm{mg}$ ) was added to a solution of 5 ( $60 \mathrm{mg}, 0.244 \mathrm{mmol}), 2,4,6$-collidine $(47 \mu \mathrm{L}, 0.353 \mathrm{mmol})$, and freshly dried AgOTf $(83 \mathrm{mg}, 0.322 \mathrm{mmol})$ in dichloromethane $(3 \mathrm{~mL})$. The suspension was stirred under argon for $1 \mathrm{~h}$ at $\mathrm{rt}$ and then cooled to $-20^{\circ} \mathrm{C}$. A solution of 6 (146 mg, $0.293 \mathrm{mmol}$ ) was added dropwise during $15 \mathrm{~min}$ to the reaction mixture in dichloromethane $(350 \mu \mathrm{L})$. After $1 \mathrm{~h}$ at $-20^{\circ} \mathrm{C}$, the mixture was allowed to warm up to rt and stirred for another $40 \mathrm{~min}$. After dilution with dichloromethane, the mixture was filtered through Celite and evaporated. FC (25 g silica, toluene/ethyl acetate 1:1, then ethyl acetate) gave 9 (83 mg, 32\% based on 5), 7 (59 mg, $37 \%), 8(18 \mathrm{mg}, 11 \%)$, and unreacted 5 (12 mg, $20 \%$ ).

Data for 7: $R_{\mathrm{f}}=0.30$ (toluene/ethyl acetate $\left.1: 1\right)$; syrup; ${ }^{1} \mathrm{H}$ NMR $(400 \mathrm{MHz}$, $\mathrm{CDCl}_{3}$ ): $\delta=7.90-7.82$ (brm, 2H, Pht), $7.74-7.72$ (m, 2H, Pht), 5.80 (dd, $1 \mathrm{H}, J=9.1,10.7 \mathrm{~Hz}, \mathrm{GlcN} 3-\mathrm{H}), 5.52(\mathrm{~d}, 1 \mathrm{H}, J=8.5 \mathrm{~Hz}, \mathrm{GlcN} 1-\mathrm{H}), 5.21$ (dd, $1 \mathrm{H}, J=9.1,10.2 \mathrm{~Hz}, \mathrm{GlcN} 4-\mathrm{H}), 4.37-4.31$ (m, $2 \mathrm{H}, \mathrm{GlcN} 6-\mathrm{H}, 2-\mathrm{H}$ ), $4.26(\mathrm{~d}, 1 \mathrm{H}, J=8.8 \mathrm{~Hz}, \mathrm{Gal} 1-\mathrm{H}), 4.21\left(\mathrm{dd}, 1 \mathrm{H}, J=2.4,12.3 \mathrm{~Hz}, \mathrm{GlcN} 6^{\prime}-\mathrm{H}\right)$, $4.05(\mathrm{dd}, 1 \mathrm{H}, J=2.6,10.7 \mathrm{~Hz}, \mathrm{Gal} 6-\mathrm{H}), 4.02(\mathrm{dd}, 1 \mathrm{H}, J=2.2,5.5 \mathrm{~Hz}, \mathrm{Gal}$
4-H), 3.96 (dd, $1 \mathrm{H}, J=5.5,7.1 \mathrm{~Hz}, \mathrm{Gal} 3-\mathrm{H}), 3.91-3.87$ (m, 2H, Gal 5-H GlcN 5-H), 3.84 (dd, $\left.1 \mathrm{H}, J=7.8,10.7 \mathrm{~Hz}, \mathrm{Gal} 6^{\prime}-\mathrm{H}\right), 3.36$ (ddd, $1 \mathrm{H}, J=3.1$, $7.1,8.8 \mathrm{~Hz}$, after addition of $\left.\mathrm{D}_{2} \mathrm{O}: \mathrm{dd}, J=7.1,8.8 \mathrm{~Hz}, \mathrm{Gal} 2-\mathrm{H}\right), 2.33(\mathrm{~d}, 1 \mathrm{H}$, $J=3.1 \mathrm{~Hz}$, exchangeable, Gal 2-OH), $2.13\left(\mathrm{~s}, 3 \mathrm{H}, \mathrm{C}(\mathrm{O}) \mathrm{CH}_{3}\right), 2.04(\mathrm{~s}, 3 \mathrm{H}$, $\left.\mathrm{C}(\mathrm{O}) \mathrm{CH}_{3}\right), 1.87\left(\mathrm{~s}, 3 \mathrm{H}, \mathrm{C}(\mathrm{O}) \mathrm{CH}_{3}\right), 1.46\left(\mathrm{~s}, 3 \mathrm{H}, \mathrm{C}\left(\mathrm{CH}_{3}\right)_{2}\right), 1.25(\mathrm{~s}, 3 \mathrm{H}$, $\left.\mathrm{C}\left(\mathrm{CH}_{3}\right)_{2}\right) ;{ }^{13} \mathrm{C} \mathrm{NMR}\left(100 \mathrm{MHz}, \mathrm{CDCl}_{3}\right): \delta=170.7,170.1,169.5,134.3,131.3$, 123.7, $110.5\left(\mathrm{CMe}_{2}\right), 98.2,89.1,78.2,74.1,73.4,72.9,71.9,70.7,68.8,68.7$, $61.8,54.5,27.9,26.0,20.8,20.6,20.4$; HR-MS (pos. FAB, NBA/CsI) calcd for $\mathrm{C}_{29} \mathrm{H}_{34} \mathrm{~N}_{4} \mathrm{O}_{14} \mathrm{Cs}[M+\mathrm{Cs}]^{+} m / z: 795.1126$, found 795.1139.

Data for 8: $R_{\mathrm{f}}=0.23$ (toluene/ethyl acetate $1: 1$ ); syrup; ${ }^{1} \mathrm{H}$ NMR $\left(400 \mathrm{MHz}, \mathrm{CDCl}_{3}\right): \delta=7.87-7.85$ (m, 2H, Pht), 7.76-7.73 (m, 2H, Pht), $5.89(\mathrm{dd}, 1 \mathrm{H}, J=9.0,10.7 \mathrm{~Hz}, \mathrm{GlcN} 3-\mathrm{H}), 5.52(\mathrm{~d}, 1 \mathrm{H}, J=8.5 \mathrm{~Hz}, \mathrm{GlcN}$ $1-\mathrm{H}), 5.17(\mathrm{dd}, 1 \mathrm{H}, J=9.1,10.2 \mathrm{~Hz}, \mathrm{GlcN} 4-\mathrm{H}), 4.40(\mathrm{~d}, 1 \mathrm{H}, J=8.6 \mathrm{~Hz}, \mathrm{Gal}$ $1-\mathrm{H}), 4.35(\mathrm{dd}, 1 \mathrm{H}, J=8.5,10.7 \mathrm{~Hz}, \mathrm{GlcN} 2-\mathrm{H}), 4.31(\mathrm{dd}, 1 \mathrm{H}, J=5.2$, $12.3 \mathrm{~Hz}, \mathrm{GlcN} 6-\mathrm{H}), 4.20$ (dd, $\left.1 \mathrm{H}, J=2.3,12.3 \mathrm{~Hz}, \mathrm{GlcN} 6^{\prime}-\mathrm{H}\right), 3.96-3.92$ $(\mathrm{m}, 1 \mathrm{H}, \mathrm{Gal}$ or GlcN 5-H), $3.93(\mathrm{dd}, 1 \mathrm{H}, J=2.1,5.7 \mathrm{~Hz}, \mathrm{Gal} 4-\mathrm{H}), 3.92$ 3.82 (m, 2 H, Gal 6-H, 6-OH), 3.84 (dd, $1 \mathrm{H}, J=5.7,6.9 \mathrm{~Hz}, \mathrm{Gal} 3-\mathrm{H}), 3.80-$ $3.76\left(\mathrm{~m}, 1 \mathrm{H}, \mathrm{Gal}\right.$ or GlcN 5-H), $3.75-3.69\left(\mathrm{~m}, 1 \mathrm{H}, \mathrm{Gal} 6^{\prime}-\mathrm{H}\right), 3.46(\mathrm{dd}, 1 \mathrm{H}$ $J=6.9,8.6 \mathrm{~Hz}, \mathrm{Gal} 2-\mathrm{H}), 2.10\left(\mathrm{~s}, 3 \mathrm{H}, \mathrm{C}(\mathrm{O}) \mathrm{CH}_{3}\right), 2.04\left(\mathrm{~s}, 3 \mathrm{H}, \mathrm{C}(\mathrm{O}) \mathrm{CH}_{3}\right)$ $1.87\left(\mathrm{~s}, 3 \mathrm{H}, \mathrm{C}(\mathrm{O}) \mathrm{CH}_{3}\right), 1.27\left(\mathrm{~s}, 3 \mathrm{H}, \mathrm{C}\left(\mathrm{CH}_{3}\right)_{2}\right), 0.87\left(\mathrm{~s}, 3 \mathrm{H}, \mathrm{C}\left(\mathrm{CH}_{3}\right)_{2}\right)$ ${ }^{13} \mathrm{C}$ NMR $\left(100 \mathrm{MHz}, \mathrm{CDCl}_{3}\right): \delta=170.8,170.1,169.5,134.0,132.0$ (br) 123.4, $110.4\left(\mathrm{CMe}_{2}\right), 99.8,88.2,81.8,77.8,75.0,73.3,71.9,70.4,68.9,62.2$ 62.1, 54.9, 27.5, 25.6, 20.7, 20.6, 20.5; HR-MS (pos. FAB, NBA/CsI) calcd for $\mathrm{C}_{29} \mathrm{H}_{34} \mathrm{~N}_{4} \mathrm{O}_{14} \mathrm{Cs}[M+\mathrm{Cs}]^{+} m / z: 795.1126$, found 795.1142 .

Data for 9: $R_{\mathrm{f}}=0.40$ (toluene/ethyl acetate $1: 1$ ); syrup; ${ }^{1} \mathrm{H}$ NMR $\left(400 \mathrm{MHz}, \mathrm{CDCl}_{3}\right): \delta=7.86-7.82(\mathrm{~m}, 4 \mathrm{H}, \mathrm{Pht}), 7.76-7.71(\mathrm{~m}, 4 \mathrm{H}, \mathrm{Pht})$ $5.86(\mathrm{dd}, 1 \mathrm{H}, J=9.0,10.7 \mathrm{~Hz}, \mathrm{GlcN} 3-\mathrm{H}), 5.78(\mathrm{dd}, 1 \mathrm{H}, J=9.1,10.8 \mathrm{~Hz}$, GlcN 3-H), 5.45 (d, $1 \mathrm{H}, J=8.5 \mathrm{~Hz}, \mathrm{GlcN} 1-\mathrm{H}), 5.44(\mathrm{~d}, 1 \mathrm{H}, J=8.5 \mathrm{~Hz}$ GlcN 1-H), 5.17 ("t", $1 \mathrm{H}, J=9.5 \mathrm{~Hz}, \mathrm{GlcN} 4-\mathrm{H}), 5.14$ ('t', $1 \mathrm{H}, J=9.5 \mathrm{~Hz}$, GlcN 4-H), $4.33-4.26$ (m, 4 H, 2 GlcN 2-H, 2 GlcN 6-H), $4.18-4.14$ (m, $2 \mathrm{H}$ $\left.2 \mathrm{GlcN} 6{ }^{\prime} \mathrm{H}\right), 4.09(\mathrm{~d}, 1 \mathrm{H}, J=8.7 \mathrm{~Hz}, \mathrm{Gal} 1-\mathrm{H}), 3.91(\mathrm{dd}, 1 \mathrm{H}, J=2.7,11 \mathrm{~Hz}$, Gal 6-H), 3.89 (ddd, $1 \mathrm{H}, J=2.3,5.1,10.2 \mathrm{~Hz}$, GlcN 5-H), 3.84 (ddd, $1 \mathrm{H}$, $J=2.3,4.2,10.1 \mathrm{~Hz}, \mathrm{GlcN} 5-\mathrm{H}), 3.74-3.65$ (m, 4H, Gal 3-H, 4-H, 5-H, 6' $\mathrm{H}), 3.32(\mathrm{dd}, 1 \mathrm{H}, J=6.8,8.7 \mathrm{~Hz}, \mathrm{Gal} 2-\mathrm{H}), 2.10\left(\mathrm{~s}, 6 \mathrm{H}, 2 \mathrm{C}(\mathrm{O}) \mathrm{CH}_{3}\right), 2.03$ (s, $\left.3 \mathrm{H}, \mathrm{C}(\mathrm{O}) \mathrm{CH}_{3}\right), 2.02\left(\mathrm{~s}, 3 \mathrm{H}, \mathrm{C}(\mathrm{O}) \mathrm{CH}_{3}\right), 1.857\left(\mathrm{~s}, 3 \mathrm{H}, \mathrm{C}(\mathrm{O}) \mathrm{CH}_{3}\right), 1.855(\mathrm{~s}$, $\left.3 \mathrm{H}, \mathrm{C}(\mathrm{O}) \mathrm{CH}_{3}\right), 1.22\left(\mathrm{~s}, 3 \mathrm{H}, \mathrm{C}\left(\mathrm{CH}_{3}\right)_{2}\right), 0.79\left(\mathrm{~s}, 3 \mathrm{H}, \mathrm{C}\left(\mathrm{CH}_{3}\right)_{2}\right) ;{ }^{13} \mathrm{C} \mathrm{NMR}$ $\left(100 \mathrm{MHz}, \mathrm{CDCl}_{3}\right): \delta=170.8,170.7,170.1,169.5,134.3,134.0,123.6,110.3$ $\left(C \mathrm{Me}_{2}\right), 99.6,98.4,87.6,81.5,77.7,77.3,73.9,73.1,71.9,71.8,70.6,70.4,68.83$, 68.77, 62.2, 61.8, 54.9, 54.4, 27.4, 25.5, 20.8, 20.7, 20.6, 20.4; HR-MS (pos. FAB, NBA/CsI) calcd for $\mathrm{C}_{49} \mathrm{H}_{52} \mathrm{~N}_{5} \mathrm{O}_{23} \mathrm{Cs}[M+\mathrm{Cs}]^{+} m / z: 1211.2107$, found 1211.2148 .

2-O-Acetyl-6- $O$-(3,4,6-tri- $O$-acetyl-2-deoxy-2-phthalimido- $\beta$-D-glucopyranosyl)-3,4- $O$-isopropylidene- $\boldsymbol{\beta}$-D-galactopyranosyl azide (10): A solution of $7(460 \mathrm{mg}, 0.694 \mathrm{mmol})$ and acetic anhydride $(656 \mu \mathrm{L}, 6.94 \mathrm{mmol})$ in pyridine $(20 \mathrm{~mL})$ was stirred for $12 \mathrm{~h}$ at $\mathrm{rt}$. The mixture was concentrated to dryness and coevaporated with toluene $(3 \times 5 \mathrm{~mL})$ and diethyl ether $(3 \times$ $5 \mathrm{~mL})$. The resulting oil was dried in vacuo to give $\mathbf{1 0}(474 \mathrm{mg}, 97 \%)$ which was used in the next step without further purification: $R_{\mathrm{f}}=0.55$ (toluene/ ethyl acetate $1: 1.5)$; syrup; ${ }^{1} \mathrm{H}$ NMR $\left(400 \mathrm{MHz} \mathrm{CDCl}_{3}\right): \delta=7.89-7.81$ (brm, 2H, Pht), 7.75-7.71 (m, 2H, Pht), $5.82(\mathrm{dd}, 1 \mathrm{H}, J=9.1,10.7 \mathrm{~Hz}$, GlcN 3-H), 5.50 (d, $1 \mathrm{H}, J=8.5 \mathrm{~Hz}$, GlcN 1-H), $5.20(\mathrm{dd}, 1 \mathrm{H}, J=9.1$, $10.2 \mathrm{~Hz}, \mathrm{GlcN} 4-\mathrm{H}$ ), 4.79 (dd, $1 \mathrm{H}, J=6.8,8.2 \mathrm{~Hz}, \mathrm{Gal} 2-\mathrm{H}$ ), 4.35 (dd, $1 \mathrm{H}$, $J=4.3,12.4 \mathrm{~Hz}, \mathrm{GlcN} 6-\mathrm{H}), 4.33$ (dd, $1 \mathrm{H}, J=8.5,10.7 \mathrm{~Hz}, \mathrm{GlcN} 2-\mathrm{H}), 4.21$ $\left(\mathrm{dd}, 1 \mathrm{H}, J=2.3,12.3 \mathrm{~Hz}, \mathrm{GlcN} 6^{\prime}-\mathrm{H}\right), 4.17(\mathrm{~d}, 1 \mathrm{H}, J=8.2 \mathrm{~Hz}, \mathrm{Gal} 1-\mathrm{H})$ 4.09-4.02 (m, 3 H, Gal 3-H, 4-H, 6-H), 3.91-3.81 (m, 3 H, GlcN 5-H, Gal 5- $\left.\mathrm{H}, 66^{\prime}-\mathrm{H}\right), 2.13\left(\mathrm{~s}, 3 \mathrm{H}, \mathrm{C}(\mathrm{O}) \mathrm{CH}_{3}\right), 2.06\left(\mathrm{~s}, 3 \mathrm{H}, \mathrm{C}(\mathrm{O}) \mathrm{CH}_{3}\right), 2.04(\mathrm{~s}, 3 \mathrm{H}$, $\left.\mathrm{C}(\mathrm{O}) \mathrm{CH}_{3}\right), 1.87\left(\mathrm{~s}, 3 \mathrm{H}, \mathrm{C}(\mathrm{O}) \mathrm{CH}_{3}\right), 1.49\left(\mathrm{~s}, 3 \mathrm{H}, \mathrm{C}\left(\mathrm{CH}_{3}\right)_{2}\right), 1.24(\mathrm{~s}, 3 \mathrm{H}$, $\left.\mathrm{C}\left(\mathrm{CH}_{3}\right)_{2}\right) ;{ }^{13} \mathrm{C} \mathrm{NMR}\left(100 \mathrm{MHz}, \mathrm{CDCl}_{3}\right): \delta=170.7,170.1,169.5,169.4,134.3$, 131.3, 123.6, $110.8\left(\mathrm{CMe}_{2}\right), 98.4,86.6,75.9,73.9,73.2,71.9,71.4,70.6,69.0$, $68.8,61.8,54.5,27.4,25.9,20.8,20.6,20.5$; HR-MS (pos. FAB, NBA/CsI) calcd for $\mathrm{C}_{31} \mathrm{H}_{36} \mathrm{~N}_{4} \mathrm{O}_{15} \mathrm{Cs}[M+\mathrm{Cs}]^{+} m / z$ : 837.1231, found 837.1251.

2-O-Acetyl-6-O-(3,4,6-tri- $O$-acetyl-2-deoxy-2-phthalimido- $\beta$-D-glucopyranosyl)- $\boldsymbol{\beta}$-D-galactopyranosyl azide (11): A solution of $\mathbf{1 0}$ (459 mg, $0.651 \mathrm{mmol})$ in $\mathrm{HOAc} / \mathrm{H}_{2} \mathrm{O} 80: 20(9 \mathrm{~mL})$ was stirred for $10 \mathrm{~h}$ at $60-$ $70^{\circ} \mathrm{C}$. The mixture was concentrated and coevaporated with toluene $(3 \times$ $5 \mathrm{~mL}$ ). Purification by FC (45 g silica, hexane/ethyl acetate 1:6) gave $\mathbf{1 1}$ (322 mg, 74\%): $R_{\mathrm{f}}=0.28$ (hexane/ethyl acetate 1:6); white solid (lyophilized from benzene); ${ }^{1} \mathrm{H}$ NMR $\left(400 \mathrm{MHz}, \mathrm{CDCl}_{3}\right): \delta=7.88-7.85(\mathrm{~m}, 2 \mathrm{H}$ Pht), $7.78-7.74$ (m, 2 H, Pht), 5.78 (dd, $1 \mathrm{H}, J=9.1,10.7 \mathrm{~Hz}, \mathrm{GlcN} 3-\mathrm{H}), 5.49$ $(\mathrm{d}, 1 \mathrm{H}, J=8.5 \mathrm{~Hz}, \mathrm{GlcN} 1-\mathrm{H}), 5.14(\mathrm{dd}, 1 \mathrm{H}, J=9.1,10.2 \mathrm{~Hz}, \mathrm{GlcN} 4-\mathrm{H})$, $4.88(\mathrm{dd}, 1 \mathrm{H}, J=8.8,9.8 \mathrm{~Hz}, \mathrm{Gal} 2-\mathrm{H}), 4.36(\mathrm{~d}, 1 \mathrm{H}, J=8.8 \mathrm{~Hz}, \mathrm{Gal} 1-\mathrm{H})$ 
$4.33(\mathrm{dd}, 1 \mathrm{H}, J=2.2,12.1 \mathrm{~Hz}, \mathrm{GlcN} 6-\mathrm{H}), 4.29(\mathrm{dd}, 1 \mathrm{H}, J=8.5,10.7 \mathrm{~Hz}$, GlcN 2-H), 4.22 (dd, $1 \mathrm{H}, J=5.3,12.4 \mathrm{~Hz}$, GlcN 6'-H), 3.98 (dd, $1 \mathrm{H}, J=7.3$, $10.3 \mathrm{~Hz}$, Gal 6-H), 3.97 (m, $1 \mathrm{H}$, Gal 4-H), 3.92 (ddd, $1 \mathrm{H}, J=2.4,5.3$, $10.2 \mathrm{~Hz}, \mathrm{GlcN} 5-\mathrm{H}$ ), 3.86 (dd, $1 \mathrm{H}, J=5.9,10.3 \mathrm{~Hz}, \mathrm{Gal} 6^{\prime}-\mathrm{H}$ ), 3.59 (ddd, $1 \mathrm{H}, J=1.2,5.9,7.2 \mathrm{~Hz}, \mathrm{Gal} 5-\mathrm{H}), 3.57(\mathrm{~m}, 1 \mathrm{H}, \mathrm{Gal} 3-\mathrm{H}), 3.08(\mathrm{brd}, 1 \mathrm{H}, J=$ $4.6 \mathrm{~Hz}, \mathrm{Gal} \mathrm{OH}), 2.87$ (brd, $1 \mathrm{H}, J=8.4 \mathrm{~Hz}, \mathrm{Gal} \mathrm{OH}), 2.15(\mathrm{~s}, 3 \mathrm{H}$, $\left.\mathrm{C}(\mathrm{O}) \mathrm{CH}_{3}\right), 2.13\left(\mathrm{~s}, 3 \mathrm{H}, \mathrm{C}(\mathrm{O}) \mathrm{CH}_{3}\right), 2.05\left(\mathrm{~s}, 3 \mathrm{H}, \mathrm{C}(\mathrm{O}) \mathrm{CH}_{3}\right), 1.87(\mathrm{~s}, 3 \mathrm{H}$, $\left.\mathrm{C}(\mathrm{O}) \mathrm{CH}_{3}\right) ;{ }^{13} \mathrm{C}$ NMR $\left(100 \mathrm{MHz}, \mathrm{CDCl}_{3}\right): \delta=170.9,170.8,170.1,169.5$, 134.4, 131.3, 123.7, 98.2, 87.8, 74.8, 72.1, 72.0, 70.5, 68.8, 67.8, 67.3, 61.8, 54.4, 20.9, 20.8, 20.6, 20.4; HR-MS (pos. FAB, NBA/CsI) calcd for $\mathrm{C}_{28} \mathrm{H}_{32} \mathrm{~N}_{4} \mathrm{O}_{15} \mathrm{Cs}[M+\mathrm{Cs}]^{+} \mathrm{m} / z$ : 797.0919, found 797.0909; anal. calcd for $\mathrm{C}_{28} \mathrm{H}_{32} \mathrm{~N}_{4} \mathrm{O}_{15}$ : C 50.60, H 4.85, N 8.43; found: C 50.84, H 4.91, N, 8.11.

\section{2- $O$-Acetyl-3,6-bis- $O$-(3,4,6-tri- $\boldsymbol{O}$-acetyl-2-deoxy-2-phthalimido- $\boldsymbol{\beta}$-D-glu-} copyranosyl)- $\boldsymbol{\beta}$-D-galactopyranosyl azide (12): Procedure $A$ : Powdered molecular sieves (4 $\AA$ ) (ca. $400 \mathrm{mg}$ ) was added to a solution of $\mathbf{1 1}(185 \mathrm{mg}$, $0.278 \mathrm{mmol}), 2,4,6$-collidine $(66 \mu \mathrm{L}, 0.497 \mathrm{mmol})$, and freshly dried AgOTf $(116 \mathrm{mg}, 0.452 \mathrm{mmol})$ in dichloromethane $(3.9 \mathrm{~mL})$. The suspension was stirred under argon for $1.5 \mathrm{~h}$ at $\mathrm{rt}$ and then cooled to $-23^{\circ} \mathrm{C}$. A solution of 6 (204 $\mathrm{mg}, 0.409 \mathrm{mmol})$ in dichloromethane $(3.9 \mathrm{~mL})$ was added dropwise during $10 \mathrm{~min}$ to the reaction mixture. After stirring for $2 \mathrm{~h}$ at $-23^{\circ} \mathrm{C}$, the mixture was allowed to warm up to rt overnight, diluted with acetonitrile, filtered through Celite and evaporated. FC (100 g silica, hexane/ethyl acetate $1: 4)$ gave $12(254 \mathrm{mg}, 84 \%): R_{\mathrm{f}}=0.43$ (hexane/ethyl acetate $\left.1: 4\right)$; white foam; ${ }^{1} \mathrm{H}$ NMR (400 MHz, $\mathrm{CDCl}_{3}$ ): $\delta=8.00-7.81$ (partly br m, $4 \mathrm{H}$, Pht), $7.78-7.75$ (m, 4 H, Pht), 5.75 (dd, $1 \mathrm{H}, J=9.1,10.7 \mathrm{~Hz}, \mathrm{GlcN} 3-\mathrm{H}$ ), 5.65 $(\mathrm{dd}, 1 \mathrm{H}, J=9.1,10.8 \mathrm{~Hz}, \mathrm{GlcN} 3-\mathrm{H}), 5.51(\mathrm{~d}, 1 \mathrm{H}, J=8.5 \mathrm{~Hz}, \mathrm{GlcN} 1-\mathrm{H})$, $5.34(\mathrm{~d}, 1 \mathrm{H}, J=8.5 \mathrm{~Hz}, \mathrm{GlcN} 1-\mathrm{H}), 5.18(\mathrm{dd}, 1 \mathrm{H}, J=9.1,10.2 \mathrm{~Hz}, \mathrm{GlcN}$ 4-H), 5.07 (dd, $1 \mathrm{H}, J=9.1,10.2 \mathrm{~Hz}, \mathrm{GlcN} 4-\mathrm{H}), 4.89$ (dd, $1 \mathrm{H}, J=8.9$, $9.7 \mathrm{~Hz}, \mathrm{Gal} 2-\mathrm{H}), 4.34$ (dd, $1 \mathrm{H}, J=4.6,12.4 \mathrm{~Hz}, \mathrm{GlcN} 6-\mathrm{H}), 4.30(\mathrm{dd}, 1 \mathrm{H}$, $J=8.5,10.7 \mathrm{~Hz}, \mathrm{GlcN} 2-\mathrm{H}), 4.28(\mathrm{dd}, 1 \mathrm{H}, J=8.4,10.8 \mathrm{~Hz}, \mathrm{GlcN} 2-\mathrm{H})$, $4.22-4.09$ (m, 3 H, GlcN 6-H, 2 GlcN 6'-H), 4.11 (d, $1 \mathrm{H}, J=8.9 \mathrm{~Hz}$, Gal $1-\mathrm{H}), 4.03(\mathrm{dd}, 1 \mathrm{H}, J=4.6,11.4 \mathrm{~Hz}$, Gal 6-H), 3.91-3.85, 3.56-3.52 (each m, each $3 \mathrm{H}$, Gal 3-H, 4-H, 5-H, 6'-H, 2 GlcN 5-H), 2.64 (br m, $1 \mathrm{H}$, Gal $\mathrm{OH}), 2.14\left(\mathrm{~s}, 3 \mathrm{H}, \mathrm{C}(\mathrm{O}) \mathrm{CH}_{3}\right), 2.10\left(\mathrm{~s}, 3 \mathrm{H}, \mathrm{C}(\mathrm{O}) \mathrm{CH}_{3}\right), 2.05(\mathrm{~s}, 3 \mathrm{H}$, $\left.\mathrm{C}(\mathrm{O}) \mathrm{CH}_{3}\right), 2.04\left(\mathrm{~s}, 3 \mathrm{H}, \mathrm{C}(\mathrm{O}) \mathrm{CH}_{3}\right), 1.86\left(\mathrm{~s}, 3 \mathrm{H}, \mathrm{C}(\mathrm{O}) \mathrm{CH}_{3}\right), 1.85(\mathrm{~s}, 3 \mathrm{H}$, $\left.\mathrm{C}(\mathrm{O}) \mathrm{CH}_{3}\right), 1.46\left(\mathrm{~s}, 3 \mathrm{H}, \mathrm{C}(\mathrm{O}) \mathrm{CH}_{3}\right) ;{ }^{13} \mathrm{C} \mathrm{NMR}\left(100 \mathrm{MHz}, \mathrm{CDCl}_{3}\right): \delta=170.8$ 170.7, 170.1, 169.5, 169.2, 168.8, 134.5, 131.3, 123.7, 98.1, 87.5, 80.2, 75.1, 72.04, 71.99, 70.8, 70.1, 69.0, 68.8, 68.7, 68.2, 67.7, 61.9, 61.7, 54.5, 54.1, 20.8, 20.7, 20.63, 20.59, 20.43, 20.38, 19.8; HR-MS (pos. FAB, NBA/CsI) calcd for $\mathrm{C}_{48} \mathrm{H}_{51} \mathrm{~N}_{5} \mathrm{O}_{24} \mathrm{Cs}[M+\mathrm{Cs}]^{+} m / z: 1214.1978$, found 1214.1947.

Procedure B: A suspension of $\mathbf{1 4}(81 \mathrm{mg}, 0.328 \mathrm{mmol}), 2,4,6$-collidine (164 $\mu \mathrm{L}, 1.25 \mathrm{mmol}$ ), and powdered molecular sieves $(4 \AA)$ (ca. $600 \mathrm{mg}$ ) in dichloromethane $(4.7 \mathrm{~mL})$ was stirred under argon for $1 \mathrm{~h}$ at $\mathrm{rt}$. After addition of freshly dried AgOTf $(316 \mathrm{mg}, 1.23 \mathrm{mmol}$ ), the mixture was cooled to $-30^{\circ} \mathrm{C}$ and a solution of $6(408 \mathrm{mg}, 0.819 \mathrm{mmol})$ in dichloromethane $(4.7 \mathrm{~mL})$ was added dropwise during $5 \mathrm{~min}$. The mixture was stirred for $1 \mathrm{~h}$ at $-30^{\circ} \mathrm{C}$, slowly warmed up to $\mathrm{rt}(2 \mathrm{~h})$, and stirred for another $20 \mathrm{~h}$ at $\mathrm{rt}$. After dilution with $\mathrm{MeOH}(5 \mathrm{~mL})$ the suspension was filtered and evaporated. Purification by FC (100 g silica, hexane/ethyl acetate 1:4) gave $12(247 \mathrm{mg}, 70 \%)$.

2- $\boldsymbol{O}$-Acetyl- $\boldsymbol{\beta}$-D-galactopyranosyl azide (14): A solution of $\mathbf{1 3}(1.14 \mathrm{~g}$, $4.55 \mathrm{mmol})$ and TMS-N $\mathrm{N}_{3}(6 \mathrm{~mL}, 45.5 \mathrm{mmol})$ in THF $(2 \mathrm{~mL})$ was stirred at $\mathrm{rt}$ for $12 \mathrm{~h}$ and then refluxed (heating bath with $90^{\circ} \mathrm{C}$ ) for $22 \mathrm{~h}$. After addition of $80 \%$ aqueous HOAc $(10 \mathrm{~mL})$, the mixture was stirred at ca. $80^{\circ} \mathrm{C}$ for $1 \mathrm{~h}$ in order to cleave the TMS ethers. The solution was concentrated and coevaporated several times with toluene. FC ( $80 \mathrm{~g}$ silica, $\mathrm{CH}_{2} \mathrm{Cl}_{2} / \mathrm{MeOH}$ 4:1) gave 14 (1.01 g, 90\%): White crystals (acetonitrile); m.p. 154 $155.5^{\circ} \mathrm{C} ; R_{\mathrm{f}}=0.50\left(\mathrm{CH}_{2} \mathrm{Cl}_{2} / \mathrm{MeOH} 4: 1\right) ;{ }^{1} \mathrm{H}$ NMR (400 MHz, [D $]$ DMSO): $\delta=5.17(\mathrm{~d}, 1 \mathrm{H}, J=5.8 \mathrm{~Hz}, 3-\mathrm{OH}), 4.88(\mathrm{~d}, 1 \mathrm{H}, J=4.2 \mathrm{~Hz}, 4-\mathrm{OH}), 4.88(\mathrm{dd}$, $1 \mathrm{H}, J=8.9,9.8 \mathrm{~Hz}, 2-\mathrm{H}), 4.76(\mathrm{t}, 1 \mathrm{H}, J=5.5 \mathrm{~Hz}, 6-\mathrm{OH}), 4.54(\mathrm{~d}, 1 \mathrm{H}, J=$ $8.9 \mathrm{~Hz}, 1-\mathrm{H}), 3.73(\mathrm{ddd}, 1 \mathrm{H}, J=3.9,3.9,<1 \mathrm{~Hz}, 4-\mathrm{H}), 3.61-3.52(\mathrm{~m}, 4 \mathrm{H}$, 3-H, 5-H, 6-H, 6'-H), 2.05 (s, 3 H, C (O) $\left.\mathrm{CH}_{3}\right) ;{ }^{13} \mathrm{C}$ NMR $(100 \mathrm{MHz}$, [D $\mathrm{D}_{6}$ DMSO): $\delta=169.7(\mathrm{C}=\mathrm{O}), 87.3,77.8,71.4,70.8,68.1,60.3,20.9\left(\mathrm{CH}_{3}\right)$; HR-MS (pos. FAB, NBA/NaI) calcd for $\mathrm{C}_{8} \mathrm{H}_{13} \mathrm{~N}_{3} \mathrm{O}_{6} \mathrm{Na}[M+\mathrm{Na}]^{+} \mathrm{m} / z$ : 270.0702, found 270.0707; anal. calcd for $\mathrm{C}_{8} \mathrm{H}_{13} \mathrm{~N}_{3} \mathrm{O}_{6}$ : C $38.87 \mathrm{H} 5.30, \mathrm{~N}$ 17.00; found: C 39.00, H 5.26, N 17.12 .

3,6-Bis- $O$-(2-acetamido-3,4,6-tri- $O$-acetyl-2-deoxy- $\boldsymbol{\beta}$-D-glucopyranosyl)2,4-di- $\boldsymbol{O}$-acetyl- $\boldsymbol{\beta}$-D-galactopyranosyl azide (15): A solution of $12(235 \mathrm{mg}$, $217 \mu \mathrm{mol})$ in $n$-butanol $(30 \mathrm{~mL})$ and ethylene diamine $(6 \mathrm{~mL})$ was stirred under $\mathrm{Ar}$ at $90^{\circ} \mathrm{C}$ for $24 \mathrm{~h}$. The solution was evaporated and the residue was coevaporated with toluene $(2 \times 5 \mathrm{~mL})$ and $\mathrm{MeOH}(2 \times 5 \mathrm{~mL})$. The crude deprotected trisaccharide azide $\left(R_{\mathrm{f}}=0.45, i \mathrm{PrOH} / 1 \mathrm{M} \mathrm{NH}_{4} \mathrm{OAc} 2: 1\right)$ was stirred with pyridine $(10 \mathrm{~mL})$ and acetic anhydride $(5 \mathrm{~mL})$ at $\mathrm{rt}$ for $18 \mathrm{~h}$. The reaction mixture was evaporated and the residue was coevaporated with toluene $(3 \times 10 \mathrm{~mL})$ and $\mathrm{MeOH}(2 \times 5 \mathrm{~mL})$ and purified by $\mathrm{FC}(80 \mathrm{~g}$ silica, $\left.\mathrm{CH}_{2} \mathrm{Cl}_{2} / \mathrm{MeOH}, 16: 1\right)$ to yield $15(185 \mathrm{mg}, 90 \%)$ : White solid; $R_{\mathrm{f}}=$ $0.30\left(\mathrm{CH}_{2} \mathrm{Cl}_{2} / \mathrm{MeOH}, 16: 1\right) ;{ }^{1} \mathrm{H}$ NMR $\left(400 \mathrm{MHz}, \mathrm{CDCl}_{3}\right): \delta=6.10(\mathrm{~d}, 1 \mathrm{H}$, $J=8.3 \mathrm{~Hz}, \mathrm{GlcN} \mathrm{NH}), 5.56(\mathrm{~d}, 1 \mathrm{H}, J=7.9 \mathrm{~Hz}, \mathrm{GlcN} \mathrm{NH}), 5.48(\mathrm{dd}, 1 \mathrm{H}, J=$ 9.2, 10.7 Hz, GlcN 3-H), 5.44 (dd, $1 \mathrm{H}, J=9.2,10.7 \mathrm{~Hz}, \mathrm{GlcN} 3-\mathrm{H}), 5.37$ (d, $1 \mathrm{H}, J=3.7 \mathrm{~Hz}, \mathrm{Gal} 4-\mathrm{H}), 5.09-5.02(\mathrm{~m}, 4 \mathrm{H}), 4.83(\mathrm{~d}, 1 \mathrm{H}, J=8.3 \mathrm{~Hz}), 4.49$ $(\mathrm{d}, 1 \mathrm{H}, J=8.9 \mathrm{~Hz}), 4.41(\mathrm{dd}, 1 \mathrm{H}, J=12.3,2.5 \mathrm{~Hz}), 4.26(\mathrm{dd}, 1 \mathrm{H}, J=12.3$, $4.5 \mathrm{~Hz}), 4.15(\mathrm{dd}, 1 \mathrm{H}, J=12.3,2.4 \mathrm{~Hz}), 4.04(\mathrm{dd}, 1 \mathrm{H}, J=12.3,3.7 \mathrm{~Hz})$, $3.91-3.83(\mathrm{~m}, 3 \mathrm{H}), 3.74-3.56(\mathrm{~m}, 4 \mathrm{H}), 3.34(\mathrm{ddd}, 1 \mathrm{H}, J=7.9,7.9,10.7 \mathrm{~Hz}$, GlcN 2-H), 2.135 (s, 3 H, C(O) $\left.\mathrm{CH}_{3}\right), 2.130$ (s, 3 H, C(O) $\left.\mathrm{CH}_{3}\right), 2.126(\mathrm{~s}, 3 \mathrm{H}$, $\left.\mathrm{C}(\mathrm{O}) \mathrm{CH}_{3}\right), 2.09\left(\mathrm{~s}, 3 \mathrm{H}, \mathrm{C}(\mathrm{O}) \mathrm{CH}_{3}\right), 2.025\left(\mathrm{~s}, 9 \mathrm{H}, 3 \mathrm{C}(\mathrm{O}) \mathrm{CH}_{3}\right), 2.019(\mathrm{~s}, 3 \mathrm{H}$, $\left.\mathrm{C}(\mathrm{O}) \mathrm{CH}_{3}\right), 1.95\left(\mathrm{~s}, 3 \mathrm{H}, \mathrm{C}(\mathrm{O}) \mathrm{CH}_{3}\right), 1.91\left(\mathrm{~s}, 3 \mathrm{H}, \mathrm{C}(\mathrm{O}) \mathrm{CH}_{3}\right) ;{ }^{13} \mathrm{C}$ NMR $\left(100 \mathrm{MHz}, \mathrm{CDCl}_{3}\right): \delta=171.13,170.69,170.61,170.43,170.40,169.58$, 169.51, 169.46, 100.19, 99.66, 88.07, 75.99, 74.89, 71.77, 71.71, 71.68, 71.12, 69.94, 69.05, 68.57, 68.51, 67.26, 61.82, 61.03, 56.06, 55.34, 23.30, 23.27, 20.89, 20.75, 20.64, 20.57; HR-MS (pos. FAB, NBA/NaI) calcd for $\mathrm{C}_{38} \mathrm{H}_{53} \mathrm{~N}_{5} \mathrm{O}_{23} \mathrm{Na}$ $[M+\mathrm{Na}]^{+} m / z: 970.3029$, found 970.3011; anal. calcd for $\mathrm{C}_{38} \mathrm{H}_{53} \mathrm{~N}_{5} \mathrm{O}_{23}: \mathrm{C}$ 48.15, H 5.64, N 7.39; found: C 48.02, H 5.85, N, 7.21.

$N^{3}$-Benzyloxycarbonyl- $N^{I}$-[3,6-bis- $O$-(2-acetamido-3,4,6-tri- $O$-acetyl-2-deoxy- $\boldsymbol{\beta}$-D-glucopyranosyl)-2,4-di- $\boldsymbol{O}$-acetyl- $\boldsymbol{\beta}$-D-galactopyranosyl]- $\boldsymbol{\beta}$-alanine amide (16): Trisaccharide $15(104 \mathrm{mg}, 110 \mu \mathrm{mol})$ was dissolved in anhydrous $\mathrm{MeOH}(4 \mathrm{~mL})$ and, after addition of dry $10 \%$ palladium on carbon catalyst (4 spatula tips), vigorously stirred under a hydrogen atmosphere (1 atm) at $0{ }^{\circ} \mathrm{C}$ for $30 \mathrm{~min}$. The mixture was filtered, evaporated, and coevaporated with anhydrous THF $(2 \times 4 \mathrm{~mL})$. The crude glycosyl amine (101 mg, white solid, $\left.R_{\mathrm{f}}=0.26, \mathrm{CH}_{2} \mathrm{Cl}_{2} / \mathrm{MeOH} 9: 1\right)$, Cbz- $\beta$-Ala-OH (43 mg, $193 \mu \mathrm{mol})$, and HOBt $(30 \mathrm{mg}, 193 \mu \mathrm{mol})$ were dissolved in anhydrous THF $(0.65 \mathrm{~mL})$ and $i \operatorname{Pr}_{2} \mathrm{NEt}(66 \mu \mathrm{L}, 386 \mu \mathrm{mol})$ and HBTU (73 mg, $\left.193 \mu \mathrm{mol}\right)$ were added. The solution was stirred at $\mathrm{rt}$ for $22 \mathrm{~h}$. Then the reaction mixture was diluted with ethyl acetate $(30 \mathrm{~mL})$ and washed with $0.5 \mathrm{~N} \mathrm{HCl}$, sat aq $\mathrm{NaHCO}_{3}$, and brine. The organic layer was dried $\left(\mathrm{Na}_{2} \mathrm{SO}_{4}\right)$, evaporated, and purified by $\mathrm{FC}\left(65 \mathrm{~g}\right.$ silica, $\mathrm{CH}_{2} \mathrm{Cl}_{2} / \mathrm{MeOH} 95: 5$ to $\left.9: 1\right)$ to give $16(83 \mathrm{mg}, 67 \%)$ as a white solid: $R_{\mathrm{f}}=0.45\left(\mathrm{CH}_{2} \mathrm{Cl}_{2} / \mathrm{MeOH} 9: 1\right)$; ${ }^{1} \mathrm{H}$ NMR (400 MHz, $\left.\mathrm{CDCl}_{3} /\left[\mathrm{D}_{6}\right] \mathrm{DMSO} 2: 1\right): \delta=8.60(\mathrm{~d}, 1 \mathrm{H}, J=7.2 \mathrm{~Hz}$, $\mathrm{NH}), 7.76(\mathrm{~d}, 1 \mathrm{H}, J=9.0 \mathrm{~Hz}, \mathrm{NH}), 7.67(\mathrm{~d}, 1 \mathrm{H}, J=9.6 \mathrm{~Hz}, \mathrm{NH}), 7.36-7.25$ $\left(\mathrm{m}, 5 \mathrm{H}, \mathrm{C}_{6} \mathrm{H}_{5}\right), 6.69\left(\mathrm{t}, 1 \mathrm{H}, J=5.5 \mathrm{~Hz}, \mathrm{CH}_{2} \mathrm{NH}\right), 5.33(\mathrm{~d}, 1 \mathrm{H}, J=3.6 \mathrm{~Hz}$, Gal 4-H), 5.18 (dd, $1 \mathrm{H}, J=9.7,10.1 \mathrm{~Hz}, \mathrm{GlcN} 3-\mathrm{H}), 5.10-4.97$ (m, 5H), $4.91(\mathrm{t}, 1 \mathrm{H}, J=9.7 \mathrm{~Hz}, \mathrm{GlcN} 4-\mathrm{H}), 4.90(\mathrm{t}, 1 \mathrm{H}, J=9.7 \mathrm{~Hz}, \mathrm{GlcN} 4-\mathrm{H}), 4.77$ $(\mathrm{d}, 1 \mathrm{H}, J=8.3 \mathrm{~Hz}), 4.69(\mathrm{~d}, 1 \mathrm{H}, J=8.6 \mathrm{~Hz}), 4.17-4.08(\mathrm{~m}, 3 \mathrm{H}), 4.01-3.84$ $(\mathrm{m}, 4 \mathrm{H}), 3.74(\mathrm{dd}, 1 \mathrm{H}, J=12.7,2.5 \mathrm{~Hz}), 3.71-3.64(\mathrm{~m}, 2 \mathrm{H}), 3.64-3.58(\mathrm{~m}$, $1 \mathrm{H}), 3.55(\mathrm{dd}, 1 \mathrm{H}, J=12.6,8.1 \mathrm{~Hz}), 3.47-3.29\left(\mathrm{~m}, 2 \mathrm{H}, \mathrm{CH}_{2} \mathrm{NH}\right), 2.60-$ 2.51, 2.44-2.36 (2m, 2H, $\left.\mathrm{CH}_{2} \mathrm{CH}_{2} \mathrm{NH}\right), 2.070,2.059,2.055,2.020,1.994$, $1.969,1.963,1.960,1.920,1.820\left(10 \mathrm{~s}, 30 \mathrm{H}, 10 \mathrm{C}(\mathrm{O}) \mathrm{CH}_{3}\right) ;{ }^{13} \mathrm{C}$ NMR $\left(100 \mathrm{MHz}, \mathrm{CDCl}_{3} /\left[\mathrm{D}_{6}\right] \mathrm{DMSO} 2: 1\right): \delta=171.79,168.88,168.82,168.74$, 168.59, 168.47, 168.41, 168.17, 168.08, 167.77, 154.93, 135.70, 126.99, 126.40, $126.17,99.35,99.17,77.20,76.88,76.36,74.82,71.43,71.03,69.77,68.48,67.62$, $67.12,67.05,66.66,64.30,60.51,60.07,52.55,51.66,35.42,34.17,21.51,21.48$, 19.40, 19.34, 19.30, 19.25, 19.20, 19.17, 19.10; HR-MS (pos. FAB, NBA/CsI) calcd for $\mathrm{C}_{49} \mathrm{H}_{66} \mathrm{~N}_{4} \mathrm{O}_{26} \mathrm{Cs}[M+\mathrm{Cs}]^{+} \mathrm{m} / z: 1259.3020$, found 1259.3053; anal. calcd for $\mathrm{C}_{49} \mathrm{H}_{66} \mathrm{~N}_{4} \mathrm{O}_{26}$ : C 52.22, H 5.90, N 4.97; found: C 51.93, H 6.05, N 5.01 .

$N^{3}$-Benzyloxycarbonyl- $N^{I}$-[3,6-bis- $O$-(2-acetamido-2-deoxy- $\beta$-D-glucopyranosyl)- $\boldsymbol{\beta}$-D-galactopyranosyl]- $\boldsymbol{\beta}$-alanine amide (17): A solution of 16 $(71 \mathrm{mg}, 63.0 \mu \mathrm{mol})$ in anhydrous $\mathrm{MeOH}(3 \mathrm{~mL})$ was treated with a solution of $\mathrm{NaOMe}$ in anhydrous $\mathrm{MeOH}(0.1 \mathrm{~N}, 1.2 \mathrm{~mL})$ and stirred for $18 \mathrm{~h}$ at rt. The solution was neutralized with cation-exchange resin (AG 50W-X2, BioRad Laboratories, pyridinium form), filtered (water was used to rinse the resin), and evaporated to give $\mathbf{1 7}(43 \mathrm{mg}, 86 \%)$ as a white foam: $R_{\mathrm{f}}=0.23$ $\left(\mathrm{MeCN} / \mathrm{H}_{2} \mathrm{O} 4: 1\right) ;{ }^{1} \mathrm{H}$ NMR $\left(400 \mathrm{MHz}, \mathrm{D}_{2} \mathrm{O}\right): \delta=7.44-7.35\left(\mathrm{~m}, 5 \mathrm{H}, \mathrm{C}_{6} \mathrm{H}_{5}\right)$, $5.13-5.07\left(\mathrm{~m}, 2 \mathrm{H}, \mathrm{CH}_{2} \mathrm{C}_{6} \mathrm{H}_{5}\right), 4.86(\mathrm{~d}, 1 \mathrm{H}, J=9.1 \mathrm{~Hz}), 4.67(\mathrm{~d}, 1 \mathrm{H}, J=$ $8.4 \mathrm{~Hz}), 4.53(\mathrm{~d}, 1 \mathrm{H}, J=8.5 \mathrm{~Hz}), 4.13(\mathrm{~d}, 1 \mathrm{H}, J=3.2 \mathrm{~Hz}), 3.94-3.84(\mathrm{~m}$, $3 \mathrm{H}), 3.82-3.60(\mathrm{~m}, 8 \mathrm{H}), 3.56-3.51(\mathrm{~m}, 1 \mathrm{H}), 3.50-3.35(\mathrm{~m}, 7 \mathrm{H}), 2.56-2.44$ $\left(\mathrm{m}, 2 \mathrm{H}, \mathrm{CH}_{2} \mathrm{CH}_{2} \mathrm{NH}\right), 1.99\left(\mathrm{~s}, 6 \mathrm{H}, 2 \mathrm{C}(\mathrm{O}) \mathrm{CH}_{3}\right) ;{ }^{13} \mathrm{C} \mathrm{NMR}\left(100 \mathrm{MHz}, \mathrm{D}_{2} \mathrm{O}\right)$ : $\delta=177.66,177.40,177.04,160.67,138.87,131.22,130.78,130.04,105.14$, $103.83,85.09,82.14,78.33,78.11,77.86,76.22,76.03,72.26,72.05,71.57$, 70.92, 70.59, 69.30, 63.08, 62.88, 58.13, 57.81, 39.13, 38.21, 24.61, 24.58; HRMS (pos. FAB, NBA/CsI) calcd for $\mathrm{C}_{33} \mathrm{H}_{50} \mathrm{~N}_{4} \mathrm{O}_{18} \mathrm{Cs}[M+\mathrm{Cs}]^{+} \mathrm{m} / z$ : 923.2174, found 923.2132 . 
$N^{3}$-Benzyloxycarbonyl- $N^{1}$-\{3,6-bis- $O$-[ $\beta$-D-galactopyranosyl-(1,4)-2-acetamido-2-deoxy- $\beta$-D-glucopyranosyl]- $\beta$-D-galactopyranosyl\}- $\beta$-alanine amide (18): Trisaccharide 17 (37.4 mg, $47.3 \mu \mathrm{mol})$, UDP-Gal $(75 \mathrm{mg}$, $123 \mu \mathrm{mol})$, and $\mathrm{MnCl}_{2} \cdot 4 \mathrm{H}_{2} \mathrm{O}\left(1 \mathrm{M}\right.$ in $\left.\mathrm{H}_{2} \mathrm{O}\right)(23.5 \mu \mathrm{L}, 23.5 \mu \mathrm{mol})$ were dissolved in HEPES buffer (50 mM, pH 7.0) $(4.7 \mathrm{~mL})$ and $\beta$-1,4-galactosyltransferase $(55 \mu \mathrm{L}, 2.75 \mathrm{U})$ and alkaline phosphatase $(7.5 \mu \mathrm{L}, 37.6 \mathrm{U})$ were added. The mixture was gently shaken at $37^{\circ} \mathrm{C}$ for $12 \mathrm{~h}$. The precipitate formed was removed by centrifugation $(23700 \mathrm{~g})$ and the supernatant purified by size-exclusion chromatography (Bio-Gel P-4, $2.5 \times 95 \mathrm{~cm}$, $50 \mathrm{~mm} \mathrm{NH}_{4} \mathrm{HCO}_{3}$ ). Product containing fractions were pooled and lyophilized. To remove contaminant UDP-Gal, the crude product was dissolved in a small amount of $\mathrm{H}_{2} \mathrm{O}$, applied to an anion-exchange column (Dowex-1 $\mathrm{X} 8, \mathrm{HCO}_{3}{ }^{-}$form $)$and eluted with $\mathrm{H}_{2} \mathrm{O}$. Lyophilization gave $\mathbf{1 8}(66.5 \mathrm{mg}$, purity $79 \%$, corresponding to $53 \mathrm{mg}$ pure $\mathbf{1 8}$, quant.) as a white fluffy powder contaminated with a small amount of HEPES buffer $(21 \%): R_{\mathrm{f}}=$ $0.56\left(i \mathrm{PrOH} / 1 \mathrm{M} \mathrm{NH} \mathrm{N}_{4} \mathrm{OAc} 2: 1\right) ;{ }^{1} \mathrm{H}$ NMR $\left(400 \mathrm{MHz}, \mathrm{D}_{2} \mathrm{O}\right): \delta=7.43-7.33$ $\left(\mathrm{m}, 5 \mathrm{H}, \mathrm{C}_{6} \mathrm{H}_{5}\right), 5.12-5.06\left(\mathrm{~m}, 2 \mathrm{H}, \mathrm{CH}_{2} \mathrm{C}_{6} \mathrm{H}_{5}\right), 4.85(\mathrm{~d}, 1 \mathrm{H}, J=9.0 \mathrm{~Hz}), 4.68$ $(\mathrm{d}, 1 \mathrm{H}, J=8.2 \mathrm{~Hz}), 4.54(\mathrm{~d}, 1 \mathrm{H}, J=8.1 \mathrm{~Hz}), 4.44(\mathrm{~d}, 1 \mathrm{H}, J=7.9 \mathrm{~Hz}), 4.41$ $(\mathrm{d}, 1 \mathrm{H}, J=7.9 \mathrm{~Hz}), 4.13(\mathrm{~d}, 1 \mathrm{H}, J=3.1 \mathrm{~Hz}), 3.95-3.35(\mathrm{~m}, 31 \mathrm{H}), 2.55-2.43$ $\left(\mathrm{m}, 2 \mathrm{H}, \mathrm{CH}_{2} \mathrm{CH}_{2} \mathrm{NH}\right), 1.97\left(\mathrm{~s}, 6 \mathrm{H}, 2 \mathrm{C}(\mathrm{O}) \mathrm{CH}_{3}\right) ;{ }^{13} \mathrm{C} \mathrm{NMR}\left(100 \mathrm{MHz}, \mathrm{D}_{2} \mathrm{O}\right)$ : $\delta=177.65,177.36,177.00,160.68,138.88,131.23,130.78,130.03,105.27$, $105.04,103.78,85.16,82.15,80.76,80.44,77.77,77.19,77.00,74.90,74.83$, $74.65,73.37,71.58,70.96,70.89,70.58,69.29,63.46,62.41,62.25,57.66,57.31$, 39.14, 38.20, 24.63, 24.60; HR-MS (pos. FAB, NBA/CsI) calcd for $\mathrm{C}_{45} \mathrm{H}_{70} \mathrm{~N}_{4} \mathrm{O}_{28} \mathrm{Cs}[M+\mathrm{Cs}]^{+} \mathrm{m} / z: 1247.3231$, found 1247.3319 .

\section{$N^{3}$-Benzyloxycarbonyl- $N^{I}$-\{3,6-bis- $O$-[ (5-acetamido-3,5-dideoxy-D-gly-} cero- $\alpha$-D-galacto-non-2-ulopyranosylonic acid)-(2,3)- $\beta$-D-galactopyranosyl-(1,4)-2-acetamido-2-deoxy- $\beta$-D-glucopyranosyl]- $\beta$-D-galactopyranosyl\}$\boldsymbol{\beta}$-alanine amide (19): Pentasaccharide $\mathbf{1 8}(37.5 \mathrm{mg}, 79 \%$ purity, $26.7 \mu \mathrm{mol})$, CMP-NeuAc $(55 \mathrm{mg}, 76 \mu \mathrm{mol}), \mathrm{MnCl}_{2} \cdot 4 \mathrm{H}_{2} \mathrm{O}\left(1 \mathrm{M}\right.$ in $\left.\mathrm{H}_{2} \mathrm{O}\right)(29 \mu \mathrm{L}$, $29 \mu \mathrm{mol}$ ), and Triton X-100 (11.6 mg in $387 \mu \mathrm{L} \mathrm{H}_{2} \mathrm{O}$ ) were dissolved in HEPES buffer (100 mM, pH 7.0) $(5.4 \mathrm{~mL})$ and $\alpha$-2,3-sialyltransferase $(193 \mu \mathrm{L}, 0.58 \mathrm{U})$ and alkaline phosphatase $(3.5 \mu \mathrm{L}, 17.4 \mathrm{U})$ were added. The mixture was gently shaken at $37^{\circ} \mathrm{C}$ for $20 \mathrm{~h}$ and another portion of CMP-NeuAc ( $15 \mathrm{mg}, 21 \mu \mathrm{mol})$ and $\alpha$-2,3-sialyltransferase $(100 \mu \mathrm{L}, 0.3 \mathrm{U})$ were added. Incubation was continued for further $22 \mathrm{~h}$ and the mixture was filtered and evaporated. Size-exclusion chromatography (Bio-Gel P-4, $\left.2.5 \times 95 \mathrm{~cm}, 100 \mathrm{~mm} \mathrm{NH}_{4} \mathrm{HCO}_{3}\right)$ gave $\mathbf{1 9}(41.8 \mathrm{mg}, 92 \%)$ as a white fluffy powder after lyophilization: $R_{\mathrm{f}}=0.12\left(i \mathrm{PrOH} / 1 \mathrm{M} \mathrm{NH} \mathrm{N}_{4} \mathrm{OAc} 3: 1\right) ;{ }^{1} \mathrm{H}$ NMR $\left(400 \mathrm{MHz}, \mathrm{D}_{2} \mathrm{O}\right): \delta=7.44-7.34\left(\mathrm{~m}, 5 \mathrm{H}, \mathrm{C}_{6} \mathrm{H}_{5}\right), 5.13-5.06(\mathrm{~m}, 2 \mathrm{H}$, $\left.\mathrm{CH}_{2} \mathrm{C}_{6} \mathrm{H}_{5}\right), 4.85(\mathrm{~d}, 1 \mathrm{H}, J=8.9 \mathrm{~Hz}), 4.68(\mathrm{~d}, 1 \mathrm{H}, J=8.3 \mathrm{~Hz}), 4.55-4.48$ $(\mathrm{m}, 1 \mathrm{H}), 4.57(\mathrm{~d}, 1 \mathrm{H}, J=7.8 \mathrm{~Hz}), 4.50(\mathrm{~d}, 1 \mathrm{H}, J=8.0 \mathrm{~Hz}), 4.13(\mathrm{~d}, 1 \mathrm{H}, J=$ $3.1 \mathrm{~Hz}), 4.11(\mathrm{t}, 1 \mathrm{H}, J=3.1 \mathrm{~Hz}), 4.08(\mathrm{t}, 1 \mathrm{H}, J=3.1 \mathrm{~Hz}), 3.96-3.46(\mathrm{~m}$, $41 \mathrm{H}), 3.39(\mathrm{~m}, 2 \mathrm{H}), 2.72(\mathrm{dd}, 2 \mathrm{H}, J=4.4,12.4 \mathrm{~Hz}), 2.56-2.44(\mathrm{~m}, 2 \mathrm{H}$, $\left.\mathrm{CH}_{2} \mathrm{CH}_{2} \mathrm{NH}\right), 2.00,1.97$ (each s, $\left.12 \mathrm{H}, 4 \mathrm{C}(\mathrm{O}) \mathrm{CH}_{3}\right), 1.80(\mathrm{t}, 2 \mathrm{H}, J=12.2 \mathrm{~Hz})$; ${ }^{13} \mathrm{C}$ NMR $\left(100 \mathrm{MHz}, \mathrm{D}_{2} \mathrm{O}\right): \delta=177.65,177.40,177.34,176.99,175.69,160.69$, $138.89,131.23,130.78,130.02$, 105.09, 104.97, 104.92, 103.80, 101.87, 85.18, $82.13,80.61,80.25,77.87,77.53,77.20,76.99,75.38,74.82,74.63,73.95,72.01$, $71.80,70.94,70.57,70.50,69.91,69.28,65.07,63.42,62.39,62.22,57.66,57.30$, $54.07,41.83,39.13,38.17,24.62,24.58,24.46$; ESI-MS $\left(\mathrm{H}_{2} \mathrm{O}\right.$, neg.) calcd for $\mathrm{C}_{67} \mathrm{H}_{103} \mathrm{~N}_{6} \mathrm{O}_{44}[M-\mathrm{H}]^{+} \mathrm{m} / z: 1695.6$, found 1696.

$N^{3}$-Benzyloxycarbonyl- $N^{l}$-\{3,6-bis-O-[ (5-acetamido-3,5-dideoxy-D-glycero- $\alpha$-D-galacto-non-2-ulopyranosylonic acid)-(2,3)- $\beta$-D-galactopyranosyl-(1,4)-[ $\alpha$-L-fucopyranosyl-(1,3) ]-2-acetamido-2-deoxy- $\beta$-D-glucopyranosyl]- $\boldsymbol{\beta}$-D-galactopyranosyl\}- $\boldsymbol{\beta}$-alanine amide (20): Saccharide $19(31 \mathrm{mg}$, $18.3 \mu \mathrm{mol})$, GDP-Fuc ( $34.5 \mathrm{mg}, 55 \mu \mathrm{mol})$, and $\mathrm{MnCl}_{2} \cdot 4 \mathrm{H}_{2} \mathrm{O}\left(1 \mathrm{M}\right.$ in $\left.\mathrm{H}_{2} \mathrm{O}\right)$ $(110 \mu \mathrm{L}, 110 \mu \mathrm{mol})$ were dissolved in MES buffer $(50 \mathrm{~mm}, \mathrm{pH} 6.0)(5.2 \mathrm{~mL})$ and $\alpha-1,3$-fucosyltransferase $(254 \mu \mathrm{L}, 0.55 \mathrm{U})$ and alkaline phosphatase $(7.7 \mu \mathrm{L}, 38.7 \mathrm{U})$ were added. The mixture was gently shaken at $37^{\circ} \mathrm{C}$ for $48 \mathrm{~h}$. The precipitate formed was removed by centrifugation $(23700 \mathrm{~g})$ and the supernatant purified by size-exclusion chromatography (Bio-Gel P-4, $2.5 \times 95 \mathrm{~cm}, 100 \mathrm{mM} \mathrm{NH_{4 }} \mathrm{HCO}_{3}$ ). Lyophilization of product containing fractions gave $20(31 \mathrm{mg}, 85 \%)$ as a white fluffy powder: $R_{\mathrm{f}}=0.31(i \mathrm{PrOH} /$ $\left.1 \mathrm{M} \mathrm{NH} \mathrm{NAc}_{4} \mathrm{OA}: 1\right) ;{ }^{1} \mathrm{H}$ NMR $\left(500 \mathrm{MHz}, \mathrm{D}_{2} \mathrm{O}\right): \delta=7.44-7.34\left(\mathrm{~m}, 5 \mathrm{H}, \mathrm{C}_{6} \mathrm{H}_{5}\right)$, $5.15-5.04\left(\mathrm{~m}, 4 \mathrm{H}, \mathrm{CH}_{2} \mathrm{C}_{6} \mathrm{H}_{5}, 2 \mathrm{Fuc} 1-\mathrm{H}\right), 4.68(\mathrm{~d}, 1 \mathrm{H}, J=8.2 \mathrm{~Hz}), 4.55-$ $4.48(\mathrm{~m}, 1 \mathrm{H}), 4.50(\mathrm{~d}, 1 \mathrm{H}, J=7.9 \mathrm{~Hz}), 4.46(\mathrm{~d}, 1 \mathrm{H}, J=7.8 \mathrm{~Hz}), 4.13(\mathrm{~d}, 1 \mathrm{H}$, $J=2.6 \mathrm{~Hz}), 4.08-4.04(\mathrm{~m}, 2 \mathrm{H}), 3.97-3.33(\mathrm{~m}, 49 \mathrm{H}), 2.73(\mathrm{dd}, 2 \mathrm{H}, J=4.5$, $12.4 \mathrm{~Hz}), 2.60-2.46\left(\mathrm{~m}, 2 \mathrm{H}, \mathrm{CH}_{2} \mathrm{CH}_{2} \mathrm{NH}\right), 2.00,1.98,1.97$ (each s, $12 \mathrm{H}$, $\left.4 \mathrm{C}(\mathrm{O}) \mathrm{CH}_{3}\right), 1.78(\mathrm{t}, 2 \mathrm{H}, J=12.1 \mathrm{~Hz}), 1.14,1.12($ each d, $6 \mathrm{H}, J=6.6 \mathrm{~Hz}$, 2 Fuc $\left.\mathrm{CH}_{3}\right) ;{ }^{13} \mathrm{C}$ NMR $\left(125 \mathrm{MHz}, \mathrm{D}_{2} \mathrm{O}\right): \delta=176.20,175.75,175.45,175.09$, $174.32,159.05,137.38,129.58,129.05,128.18,103.21,102.29,102.00,100.19$,
$99.34,83.57,80.52,76.37,76.00,75.78,75.63,75.56,75.39,73.69,72.65,72.47$, $72.43,70.03,69.92,68.95,68.84,68.45,68.03,67.41,63.37,62.22,60.24,56.75$, $56.28,52.42,51.11,40.41,40.25,37.34,36.28,31.08,25.04,24.55,23.02,22.92$, 22.78, 16.02, 15.93; MALDI-MS $\left(\mathrm{H}_{2} 0\right.$, neg.) calcd for $\mathrm{C}_{79} \mathrm{H}_{124} \mathrm{~N}_{6} \mathrm{O}_{52} \mathrm{Na}[M+$ $\mathrm{Na}]^{+} m / z: 2011.7$, found 2011.

$N^{3}$-(4,4-Difluoro-5,7-dimethyl-4-bora-[3a,4a]-diaza-s-indacene-3-propionyl)- $N^{I}$-\{3,6-bis- $O$-[ (5-acetamido-3,5-dideoxy-D-glycero- $\alpha$-D-galacto-non2-ulopyranosylonic acid)-(2,3)- $\beta$-D-galactopyranosyl-(1,4)-[ $\alpha$-L-fucopyranosyl-(1,3) ]-2-acetamido-2-deoxy- $\beta$-D-glucopyranosyl]- $\beta$-D-galactopyranosyl\}- $\beta$-alanine amide (2): A mixture of $20(21.7 \mathrm{mg}, 10.9 \mu \mathrm{mol}), 10 \%$ palladium on carbon catalyst (one spatula tip), $\mathrm{MeOH}(0.5 \mathrm{~mL})$, and $\mathrm{H}_{2} \mathrm{O}$ $(0.5 \mathrm{~mL})$ was vigorously stirred under an hydrogen atmosphere $(1 \mathrm{~atm})$ at $\mathrm{rt}$ for $30 \mathrm{~min}$. The mixture was filtered through Celite and evaporated. The crude nonasaccharide amine $\left(19.3 \mathrm{mg}, R_{\mathrm{f}}=0.07, i \mathrm{PrOH} / 1 \mathrm{M} \mathrm{NH}_{4} \mathrm{OAc} 2: 1\right)$ was dissolved in DMF $(300 \mu \mathrm{L})$ and $\mathrm{H}_{2} \mathrm{O}(100 \mu \mathrm{L})$ and stirred with 21 $(7.4 \mathrm{mg}, 19 \mu \mathrm{mol})$ and $\mathrm{Et}_{3} \mathrm{~N}(11 \mu \mathrm{L}, 79.5 \mu \mathrm{mol})$ for $1 \mathrm{~h}$ at rt. Ten drops of a solution of $\mathrm{NH}_{3}$ in $\mathrm{MeOH}$ (saturated at $0^{\circ} \mathrm{C}$ ) were added and stirring was continued for $15 \mathrm{~min}$. The mixture was evaporated and purified by sizeexclusion chromatography (Bio-Gel P-2, $2.5 \times 70 \mathrm{~cm}, 100 \mathrm{~mm} \mathrm{NH}_{4} \mathrm{HCO}_{3}$ ) to give, after lyophilization, $\mathbf{2}(20.7 \mathrm{mg}, 89 \%)$ as an orange solid: $R_{\mathrm{f}}=0.35$ $\left(i \mathrm{PrOH} / 1 \mathrm{M} \mathrm{NH} \mathrm{NH}_{4} \mathrm{OAc} 2: 1\right) ;{ }^{1} \mathrm{H}$ NMR $\left(400 \mathrm{MHz}, \mathrm{D}_{2} \mathrm{O}\right): \delta=7.44(\mathrm{~s}, 1 \mathrm{H})$, $7.05-7.02(\mathrm{~m}, 1 \mathrm{H}), 6.31-6.27(\mathrm{~m}, 2 \mathrm{H}), 5.10(\mathrm{~d}, 1 \mathrm{H}, J=3.9 \mathrm{~Hz}$, Fuc $1-\mathrm{H})$, $5.07(\mathrm{~d}, 1 \mathrm{H}, J=3.9 \mathrm{~Hz}$, Fuc 1-H), $4.67(\mathrm{~d}, 1 \mathrm{H}, J=8.5 \mathrm{~Hz}), 4.53-4.46(\mathrm{~m}$, $1 \mathrm{H}), 4.50(\mathrm{~d}, 1 \mathrm{H}, J=7.5 \mathrm{~Hz}), 4.46(\mathrm{~d}, 1 \mathrm{H}, J=7.7 \mathrm{~Hz}), 4.11(\mathrm{~d}, 1 \mathrm{H}, J=$ $2.6 \mathrm{~Hz}), 4.09-4.03(\mathrm{~m}, 2 \mathrm{H}), 3.96-3.31(\mathrm{~m}, 49 \mathrm{H}), 3.17-3.10(\mathrm{~m}, 2 \mathrm{H}), 2.77-$ $2.70(\mathrm{~m}, 2 \mathrm{H}), 2.70-2.56\left(\mathrm{~m}, 2 \mathrm{H}, \mathrm{CH}_{2} \mathrm{CH}_{2} \mathrm{NH}\right), 2.55-2.45(\mathrm{~m}, 2 \mathrm{H}), 2.49(\mathrm{~s}$, $\left.3 \mathrm{H}, \mathrm{Ar}-\mathrm{CH}_{3}\right), 2.23$ (s, $\left.3 \mathrm{H}, \mathrm{Ar}-\mathrm{CH}_{3}\right), 2.00,1.97,1.96$ (each s, $12 \mathrm{H}$, $\left.4 \mathrm{C}(\mathrm{O}) \mathrm{CH}_{3}\right), 1.78(\mathrm{t}, 2 \mathrm{H}, J=12.1 \mathrm{~Hz}), 1.13,1.11$ (each d, $6 \mathrm{H}, J=6.6 \mathrm{~Hz}$, 2Fuc $\left.\mathrm{CH}_{3}\right)$; ESI-MS $\left(\mathrm{H}_{2} \mathrm{O}\right.$, neg.) calcd for ${ }^{12} \mathrm{C}_{84}{ }^{13} \mathrm{CH}_{130} \mathrm{BF}_{2} \mathrm{~N}_{8} \mathrm{O}_{51}[M-\mathrm{H}]$ $m / z: 2128.8$, found 2129 .

5-[2-(4,4-Difluoro-5,7-dimethyl-4-bora-[3a,4a]-diaza-s-indacene-3-propionylamino)ethylaminocarbonyl]pentyl (5-acetamido-3,5-dideoxy-D-glycero- $\alpha$-D-galacto-non-2-ulopyranosylonic acid)-(2,3)- $\beta$-D-galactopyranosyl(1,4)-[ $\alpha$-L-fucopyranosyl-(1,3) $]$-2-acetamido-2-deoxy- $\beta$-D-glucopyranoside (23): A solution of $22(3 \mathrm{mg}, 3.07 \mu \mathrm{mol}), 21(1.5 \mathrm{mg}, 3.7 \mu \mathrm{mol})$, and $\mathrm{Et}_{3} \mathrm{~N}$ $(1 \mu \mathrm{L}, 7.2 \mu \mathrm{mol})$ in DMF $(60 \mu \mathrm{L})$ was stirred for $2 \mathrm{~h}$ at rt. Two drops of a solution of $\mathrm{NH}_{3}$ in $\mathrm{MeOH}$ (saturated at $0^{\circ} \mathrm{C}$ ) were added and stirring was continued for $1 \mathrm{~h}$. The mixture was evaporated and purified by sizeexclusion chromatography (Bio-Gel P-2, $2.5 \times 70 \mathrm{~cm}, 50 \mathrm{mM} \mathrm{NH}_{4} \mathrm{HCO}_{3}$ ) to give, after lyophilization, $\mathbf{2 3}(3.2 \mathrm{mg}, 83 \%)$ as an orange solid: $R_{\mathrm{f}}=0.58$ $\left(i \mathrm{PrOH} / 1 \mathrm{M} \mathrm{NH}_{4} \mathrm{OAc} 2: 1\right) ;{ }^{1} \mathrm{H}$ NMR $\left(400 \mathrm{MHz}, \mathrm{D}_{2} \mathrm{O}\right): \delta=7.45(\mathrm{~s}, 1 \mathrm{H}), 7.04$ $(\mathrm{d}, 1 \mathrm{H}, J=4.0 \mathrm{~Hz}), 6.35(\mathrm{~d}, 1 \mathrm{H}, J=4.0 \mathrm{~Hz}), 6.30(\mathrm{~s}, 1 \mathrm{H}), 5.07(\mathrm{~d}, 1 \mathrm{H}, J=$ $4.0 \mathrm{~Hz}), 4.50(\mathrm{~d}, 1 \mathrm{H}, J=7.8 \mathrm{~Hz}), 4.41(\mathrm{~d}, 1 \mathrm{H}, J=8.1 \mathrm{~Hz}), 4.08(\mathrm{dd}, 1 \mathrm{H}, J=$ $3.1,9.8 \mathrm{~Hz}), 3.95-3.40(\mathrm{~m}, 23 \mathrm{H}), 3.34-3.21(\mathrm{~m}, 4 \mathrm{H}), 3.17(\mathrm{t}, 2 \mathrm{H}, J=$ $7.2 \mathrm{~Hz}), 2.75(\mathrm{dd}, 1 \mathrm{H}, J=4.6,12.4 \mathrm{~Hz}), 2.66(\mathrm{t}, 2 \mathrm{H}, J=7.2 \mathrm{~Hz}), 2.50(\mathrm{~s}$, $3 \mathrm{H}$, arom. $\left.\mathrm{CH}_{3}\right), 2.25\left(\mathrm{~s}, 3 \mathrm{H}\right.$, arom. $\left.\mathrm{CH}_{3}\right), 2.07-2.01(\mathrm{~m}, 2 \mathrm{H}), 2.02(\mathrm{~s}, 3 \mathrm{H}$, $\left.\mathrm{C}(\mathrm{O}) \mathrm{CH}_{3}\right), 1.97\left(\mathrm{~s}, 3 \mathrm{H}, \mathrm{C}(\mathrm{O}) \mathrm{CH}_{3}\right), 1.80(\mathrm{t}, 1 \mathrm{H}, J=12.2 \mathrm{~Hz}), 1.47-1.38(\mathrm{~m}$, $4 \mathrm{H}), 1.20-1.11(\mathrm{~m}, 2 \mathrm{H}), 1.15(\mathrm{~d}, 3 \mathrm{H}, J=6.6 \mathrm{~Hz}) ;{ }^{13} \mathrm{C}$ NMR $(125 \mathrm{MHz}$, $\left.\mathrm{D}_{2} \mathrm{O}\right): \delta=177.7,176.0,175.8,174.8,174.4,162.5,156.4,147.4,136.2,133.9$, 129.4, 125.6, 122.0, 117.2, 102.4, 101.7, 100.2, 99.4, 76.5, 76.0, 75.6, 74.1, 73.7, 72.7, 72.5, 71.0, 70.1, 70.0, 69.0, 68.9, 68.5, 68.1, 67.5, 63.4, 62.2, 60.4, 56.6, 52.5, 40.5, 39.6, 39.1, 36.4, 35.7, 29.0, 25.6, 25.5, 25.1, 23.0, 22.8, 16.1, 15.1, 11.3; ESI-MS $\left(\mathrm{H}_{2} \mathrm{O}\right.$, neg.) calcd for $\mathrm{C}_{53} \mathrm{H}_{80} \mathrm{BF}_{2} \mathrm{~N}_{6} \mathrm{O}_{25}[M-\mathrm{H}]^{+} m / z: 1249.5$, found 1249.5

Biotin-conjugated sialyl Lewis x (25): NHS-biotin $24(1.0 \mathrm{mg}, 2.8 \mu \mathrm{mol})$ and dry triethylamine $(70 \mu \mathrm{L}, 5.1 \mu \mathrm{mol})$ were added to a solution of $\mathbf{2 2}(2.5 \mathrm{mg}$, $2.6 \mu \mathrm{mol})$ in dry DMF $(330 \mu \mathrm{L})$. The reaction flask was covered in foil and the reaction allowed to stir at $\mathrm{rt}$ for 24 hours. Solvent was evaporated under reduced pressure, and the resulting residue was purified by size-exclusion chromatography (Bio-Gel P-2, $2.5 \times 65 \mathrm{~cm}, 50 \mathrm{~mm} \mathrm{NH}_{4} \mathrm{HCO}_{3}$ ). Lyophilization gave 25 as a white foam $(2.0 \mathrm{mg}, 65 \%) .{ }^{1} \mathrm{H}$ NMR $\left(400 \mathrm{MHz}, \mathrm{D}_{2} \mathrm{O}\right): \delta=$ $8.29(\mathrm{~s}, 1 \mathrm{H}), 4.94(\mathrm{dd}, 1 \mathrm{H}, J=3.7 \mathrm{~Hz}), 4.46(\mathrm{dd}, 1 \mathrm{H}, J=8.1,5.1 \mathrm{~Hz}), 4.37(\mathrm{~d}$, $2 \mathrm{H}, J=7.9 \mathrm{~Hz}), 4.27(\mathrm{dd}, 1 \mathrm{H}, J=7.7,4.3 \mathrm{~Hz}), 3.93(\mathrm{dd}, 1 \mathrm{H}, J=9.8,3.1 \mathrm{~Hz})$, $3.85(\mathrm{~d}, 1 \mathrm{H}, J=10.2 \mathrm{~Hz}), 3.78-3.68(\mathrm{~m}, 9 \mathrm{H}), 3.62(\mathrm{~d}, 1 \mathrm{H}, J=3.1 \mathrm{~Hz})$ $3.57-3.43(\mathrm{~m}, 13 \mathrm{H}), 3.38(\mathrm{dd}, 1 \mathrm{H}, J=21.0,13.1 \mathrm{~Hz}), 3.20-3.17(\mathrm{~m}, 6 \mathrm{H})$, $2.84(\mathrm{dd}, 1 \mathrm{H}, J=13.2,5.0 \mathrm{~Hz}), 2.65-2.55(\mathrm{~m}, 3 \mathrm{H}), 2.09(\mathrm{dd}, 5 \mathrm{H}, J=14.6$ $7.2 \mathrm{~Hz}), 1.88(\mathrm{~s}, 3 \mathrm{H}), 1.87(\mathrm{~s}, 3 \mathrm{H}), 1.64(\mathrm{t}, 1 \mathrm{H}, J=12.3 \mathrm{~Hz}), 1.50-1.41(\mathrm{~m}$, $4 \mathrm{H}), 1.26-1.23(\mathrm{~m}, 2 \mathrm{H}), 1.17-1.12(\mathrm{~m}, 4 \mathrm{H}), 1.01(\mathrm{~d}, 3 \mathrm{H}, J=7.0 \mathrm{~Hz})$ ${ }^{13} \mathrm{C}$ NMR $\left(125 \mathrm{MHz}, \mathrm{D}_{2} \mathrm{O}\right): \delta=176.3,176.2,174.2,173.0,170.2,100.8,100.1$, $98.8,97.8,74.8,74.5,74.1,72.6,72.1,71.1,70.9,69.5,68.8,68.6,68.4,68.4$ $67.5,66.9,66.5,65.8,61.8,61.3,60.6,59.5,59.4,55.0,54.5,50.9,39.0,38.9$ 
37.8, 35.0, 34.7, 27.5, 27.0, 26.9, 24.3, 24.2, 23.9, 21.5, 21.4, 21.2, 19.2, 14.4, 9.5; ESI-MS $\left(\mathrm{H}_{2} \mathrm{O}\right.$, neg.) calcd for $\mathrm{C}_{49} \mathrm{H}_{82} \mathrm{~N}_{6} \mathrm{O}_{26} \mathrm{~S}[M-\mathrm{H}]^{+} m / z: 1202.3$, found 1202; ESI-MS $\left(\mathrm{H}_{2} \mathrm{O}\right.$, pos.) calcd for $\mathrm{C}_{49} \mathrm{H}_{82} \mathrm{~N}_{6} \mathrm{O}_{26} \mathrm{~S}[M-\mathrm{H}+2 \mathrm{Na}]^{+} m / z$ : 1248.3 , found 1248 .

RT-PCR and construction of the expression vector for $h \mathrm{~L}$ - and $\mathrm{hE}$-selectin : Human homologue of L-selectin (hL-selectin) was amplified with total RNA from human spleen tissue (Clontech, Palo Alto, CA) by RT-PCR. Total RNA was used for reverse transcription (RT) by using reverse transcriptase, following the supplier's protocol (Life Technologies, Gaithersburg, MD). This RT product was used for PCR. For amplification of L-selectin, the forward primer (5'-CGGAATTCATGATATTTCCATGGAAATGTCAG-3'; with internal Eco RI site underlined) and the reverse primer (5'-GTTCTAGATTAATATGGGTCATTCATACTTCTC-3'; with internal $\mathrm{Xba}$ I site underlined) were used in $100 \mu \mathrm{L}$ reaction mixture by using Pfu DNA polymerase (Stratagene, San Diego, CA) following the hotstart method. After 30 cycles, the reaction mixture was analyzed by agarose gel electrophoresis which showed the generation of a single major band of about $1.06 \mathrm{~kb}$. The fragment was purified by agarose gel electrophoresis, followed by Geneclean. Subcloning in pcDNA.3 (Invitrogen, Carlsbad, CA) was done with Eco RI and $X b a$ I digestion, followed by ligation. Transformation was carried out following usual procedure. The clone containing the plasmid DNA was grown in LB-ampicillin containing medium. Plasmid DNA was isolated and confirmed by double-stranded sequencing at TSRI core facility.

Similarly, hE-selectin was amplified with the forward primer (5'-ATAAGAATGCGGCCGCTAATGATTGCTTCACAGTTTCTCTC-3'; with internal Not I site underlined) and the reverse primer (5'-GCTCTAGAAACTTAAAGGATGTAAGAAGGCTTTTG-3'; with internal $\mathrm{Xba}$ I site underlined). The full length cDNA was amplified by using $P f u$ DNA polymerase. The amplification yielded a major band of $1.825 \mathrm{~kb}$. This was purified by agarose gel electrophoresis, followed by Geneclean. Subcloning in pcDNA. 3 was carried out by using Not I and $\mathrm{Xba}$ I. The clone containing the plasmid DNA was grown in LB-ampicillin medium. The plasmid DNA was isolated and verified by double-stranded sequencing in the TSRI core facility.

Transfection of cDNAs in CHO-K1 and isolation of stable cell lines by ELISA : CHO-K1 cells were routinely grown in MEM medium containing $5 \%$ fetal calf serum and $1 \%$ glutamine. The plasmid DNAs for full length hL-selectin or hE-selectin were used to transfect freshly grown $\mathrm{CHO}-\mathrm{K} 1$ cells with Lifofectamine, following the procedure of the supplier (Life Technologies). After 48 hrs of transfection, cells were digested with trypsin and replated on medium containing G418. After about two weeks, individual colonies were isolated by trypsin digestion, and were grown in 48 well plates containing G418 in the medium. The cells were incubated at $37^{\circ} \mathrm{C}$ and used for selection in an ELISA assay as follows: the G418 resistant transfected cells (about $10^{4}$ cells) expressing selectin were added into a polylysine-coated Falcon 96 well plate (a replica plate for each was also made and saved) and incubated overnight at $37^{\circ} \mathrm{C}$. The medium was removed and the cells were washed with PBS. The plates were blocked for one hour with blocking buffer (PBS $+1 \%$ human serum [Sigma]) at room temperature. These were washed three times with PBS. Primary antibody (50 $\mu \mathrm{L}$ per well, Pharmingen, San Diego, CA) diluted in the blocking buffer (1:500) was added and incubated for $2 \mathrm{hrs}$ at $\mathrm{rt}$ (or $4{ }^{\circ} \mathrm{C}$ overnight). The cells were washed three times with PBS, and then sheep anti-mouse IgG-HRP conjugated antibody (50 $\mu \mathrm{L}$ per well, Amersham) diluted in the blocking buffer (1:1000) was added. The cells were incubated one hour at $\mathrm{rt}$ and then washed three times with PBS. The color was developed by the addition of TMB peroxidase substrate $(50 \mu \mathrm{L}$ per well; Pierce, Rockford, IL). The reaction was quenched with $1 \mathrm{M}$ phosphoric acid $(50 \mu \mathrm{L}$ per well), and the plates were read at $\mathrm{OD}_{450}$. The wells containing cells with maximal $\mathrm{OD}_{450}$ by ELISA were selected. The expression of selectins by these cells was also verified by sandwich ELISA. Plates were coated with anti-selectin antibody, incubated overnight at $4{ }^{\circ} \mathrm{C}$, and then used for ELISA as above. Two clones for each (hL-selectin and hE-selectin) were selected. A control cell line incorporating the vector only was selected by G418 resistance. The cells with $\mathrm{OD}_{450}$ over this control cell line were considered positive in the assay. Two clones for each of the selectin-expressing stable cell lines were selected for final sorting by a cell sorter.

FACS analysis and isolation of transfected clones: The cell lines selected by ELISA were grown until confluency in MEM medium containing $5 \%$ fetal calf serum. These $\left(\approx 10^{7}\right.$ cells $\left.\mathrm{mL}^{-1}\right)$ were digested with trypsin, collected in a Falcon tube and washed three times with PBS for staining in solution by using anti-selectin (either hL- or hE-) antibody as follows: the cells were incubated for one hour in the blocking buffer (PBS containing $0.5 \%$ human serum) at rt. The blocking buffer was removed by washing the cells in PBS. Anti-selectin antibody diluted in the blocking buffer (1:500) was added and the cells were incubated at $\mathrm{rt}$ for $45 \mathrm{~min}$. These cells were washed four times with PBS at room temperature, and TRITC-conjugated anti-mouse IgG antibody was used as a secondary antibody (diluted 1:1000 in blocking buffer). Incubation was carried out for one hour (in the dark) at room temperature. The cells were washed again four times with PBS, finally suspended in $400 \mu \mathrm{L}$ of PBS containing $0.1 \%$ bovine serum albumine (BSA), and $25 \mathrm{~mm}$ HEPES for FACS analysis. $0.1 \%$ of the maximally intense cells were sorted out (Vantage, TSRI core facility) and collected in $200 \mu \mathrm{L}$ of fetal calf serum. These were then transferred to a T25-tissue culture flask containing MEM medium and placed in a $\mathrm{CO}_{2}$ incubator at $37^{\circ} \mathrm{C}$ for two weeks of growth. These cells were used for immunofluorescence microscopy.

Activation of HUVEC cells: HUVEC monolayers grown in endothelial cell growth medium (Cell Applications, Inc., San Diego, CA) were seeded at the second passage onto $35 \mathrm{~mm}$ glass coverslips treated with fibronectin (treated with $20 \mu \mathrm{g} \mathrm{mL}^{-1}$ for $1-2 \mathrm{hrs}$ ). These were grown to confluency in complete M199 culture medium in a $5 \% \mathrm{CO}_{2}$ incubator at $37^{\circ} \mathrm{C}$. The cells were activated for $4 \mathrm{~h}$ with LPS $\left(100 \mathrm{ng} \mathrm{mL}^{-1}\right)$ following the method of Welply et al. ${ }^{[12]}$ These were washed three times with PBS (Dulbecco phosphate-buffered saline solution without calcium and magnesium salts; Irvine Scientific, CA) and fixed in 1-2\% freshly prepared formaldehyde (made in PBS without calcium and magnesium salts) for 35-50 min at room temperature. Before staining, the cells were washed twice with $0.1 \mathrm{M}$ glycine in PBS and then incubated in blocking buffer $(0.5 \%$ human serum in PBS) for $45 \mathrm{~min}$.

For experiments involving CHO-K1, cells (about $10^{6}$ cells per plate) were plated in a $100 \mathrm{~cm}$ plate containing fibronectin treated cover slips. The cells were grown in MEM medium (containing $5 \%$ fetal calf serum and $1 \% \mathrm{~L}$ glutamine) until $80-90 \%$ confluency on the cover slips was observed under a light microscope. The cells were washed twice in PBS and then fixed in formaldehyde, as above.

Immunofluorescence microscopy: For detection of E-selectin expression, the cells were washed and then incubated for $1 \mathrm{~h}$ at room temperature in $50 \mu \mathrm{L}$ of blocking buffer containing 1:100 dilution of affinity purified antihuman CD62E monoclonal antibody (Pharmingen, San Diego, CA). These were washed three times in PBS, and incubated for $45 \mathrm{~min}$ at room temperature in 1:100 dilution of tetramethylrhodamine isothiocyanate (TRITC)-conjugated anti-mouse IgG (Fab specific) in blocking buffer. For study of the fluorescent synthetic ligands, the cells were incubated for $45 \mathrm{~min}$ at room temperature in BODIPY-conjugated oligosaccharide ( $6.5 \mu \mathrm{M}$ in PBS containing $1 \mathrm{~mm}$ each of calcium and magnesium salts). Cells were washed four times with PBS (containing calcium and magnesium) and mounted on microscope slides with approximately $20 \mu \mathrm{L}$ of mounting medium (Molecular Probes, Inc., Eugene, OR). These were visualized by using a Nikon Microphot-FXA microscope. Pictures were taken with a digital CCD camera and were processed with Adobe Photoshop.

\section{Acknowledgment}

This work was kindly supported by the NSF and NIH. V.W. acknowledges a fellowship from the Deutsche Forschungsgemeinschaft. Sequencing of DNA, mass spectrometry, NMR spectroscopy, and FACS analysis were done at the core facilities of TSRI. The authors kindly acknowledge Arlene A. Hipolito and the laboratory of Dr. Shelley Halpain for help in the immunofluorescence experiments. We thank Dr. Phil Trotter for his help with FACS analysis.

[1] a) T. A. Springer, Annu. Rev. Physiol. 1995, 57, 827-872; b) L. A Lasky, Annu. Rev. Biochem. 1995, 64, 113-139; c) P. Sears, C.-H Wong, Proc. Natl. Acad. Sci. USA 1996, 93, 12086-12093.

[2] a) M. L. Phillips, E. Nudelman, F. C. A. Gaeta, M. Perez, A. K. Singhal, S.-I. Hakomori, J. C. Paulson, Science 1990, 250, 1130-1132; b) G. Walz, A. Aruffo, W. Kolanus, M. Bevilacqua, B. Seed, Science 
1990, 250, 1132-1135; c) M. J. Polley, M. L. Phillips, E. Wayner, E. Nudelman, A. K. Singhal, S.-I. Hakomori, J. C. Paulson, Proc. Natl. Acad. Sci. USA 1991, 88, 6224-6228; d) J. B. Lowe, L. M. Stoolman, R. P. Nair, R. D. Larsen, T. L. Berhend, R. M. Marks, Cell 1990, 63, 475 -484; e) S. E. Goelz, C. Hession, D. Goff, B. Griffiths, R. Tizard, B. Newman, G. Chi-Rosso, R. Lobb, Cell 1990, 63, 1349-1356; f) Q. Zhou, K. L. Moore, D. F. Smith, A. Varki, R. P. McEver, R. D. Cummings, J. Cell Biol. 1991, 115, 557-564; g) M. Tiemeyer, S. J. Swiedler, M. Ishihara, M. Moreland, H. Schweingruber, P. Hirtzer, B. K. Brandley, Proc. Natl. Acad. Sci. USA 1991, 88, 1138-1142; h) C. Foxall, S. R. Watson, D. Dowbenko, C. Fennie, L. A. Lasky, M. Kiso, A. Hasegawa, D. Asa, B. K. Brandley, J. Cell Biol. 1992, 117, 895-902.

[3] E. L. Berg, M. K. Robinson, O. Mansson, E. C. Butcher, J. L. Magnani, J. Biol. Chem. 1991, 266, 14869-14872.

[4] a) C.-T. Yuen, A. M. Lawson, W. Chai, M. Larkin, M. S. Stoll, A. C Stuart, F. X. Sullivan, T. J. Ahern, T. Feizi, Biochemistry 1992, 31, 9126-9131; b) P. J. Green, T. Tamatani, T. Watanabe, M. Miyasaka, A. Hasegawa, M. Kiso, C.-T. Yuen, M. S. Stoll, T. Feizi, Biochem. Biophys. Res. Commun. 1992, 188, 244 -251; c) P. J. Green, C.-T. Yuen, R. A. Childs, W. Chai, M. Miyasaka, R. Lemoine, A. Lubineau, B. Smith, H. Ueno, K. C. Nicolaou, T. Feizi, Glycobiology 1995, 5, 2938; d) B. K. Brandley, M. Kiso, S. Abbas, P. Nikrad, O. Srivasatava, C. Foxall, Y. Oda, A. Hasegawa, Glycobiology 1993, 3, 633-641; e) S. Hemmerich, C. R. Bertozzi, H. Leffler, S. D. Rosen, Biochemistry 1994, 33, 4820-4829; f) E. V. Chandrasekaran, R. K. Jain, R. D. Larsen, K. Wlasichuk, K. L. Matta, Biochemsitry 1994, 34, 1210-1217.

[5] H. Maaheimo, R. Renkonen, J. P. Turunen, L. Penttila, O. Renkonen, Eur. J. Biochem. 1995, 234, 616-625.

[6] a) S. A. DeFrees, F. C. A. Gaeta, Y.-C. Lin, Y. Ichikawa, C.-H. Wong, J. Am. Chem. Soc. 1993, 115, 7549-7550; b) S. A. DeFrees, W. Kosch, W. Way, J. C. Paulson, S. Sabesan, R. L. Halcomb, D.-H. Huang, Y. Ichikawa, C.-H. Wong, J. Am. Chem. Soc. 1995, 117, 66-79; c) C.-H. Lin, M. Shimazaki, C.-H. Wong, M. Koketsu, L. R. Juneja, M. Kim, Bioorg. Med. Chem. 1995, 3, 1625-1630.

[7] G. Baisch, R. Öhrlein, Angew. Chem. 1996, 108, 1949-1952; Angew. Chem. Int. Ed. Engl. 1996, 35, 1812-1815.

[8] H. Miyauchi, M. Yuri, M. Tanaka, N. Kawamura, M. Hayashi, Bioorg. Med. Chem. Lett. 1997, 7, 989-992.

[9] G. Kretzschmar, U. Sprengard, H. Kunz, E. Bartnik, W. Schmidt, A. Töpfer, B. Hörsch, M. Krause, D. Seiffge, Tetrahedron 1995, 51, 13015-13030.

[10] U. Sprengard, M. Schudock, W. Schmidt, G. Kretzschmar, H. Kunz, Angew. Chem. 1996, 108, 359-362; Angew. Chem. Int. Ed. Engl. 1996, $35,321-324$

[11] A. Seppo, J. P. Turunen, L. Penttila, A. Keane, O. Renkonen, R. Renkonen, Glycobiology 1996, 6, 65-71.

[12] J. K. Welply, S. Z. Abbas, P. Scudder, J. L. Keene, K. Broschat, S. Casnocha, C. Gorka, C. Steininger, S. C. Howard, J. J. Schmuke, M. Graneto, J. M. Rotsaert, I. D. Manger, G. S. Jacob, Glycobiology 1994, 4, 259-265.

[13] a) R. Roy, W. K. C. Park, O. P. Srivastava, C. Foxall, Bioorg. Med. Chem. Lett. 1996, 6, 1399-1402; b) D. Zanini, R. Roy, W. K. C. Park, C. Foxall, O. P. Srivastava, XVIIIth Int. Carbohydr. Symp., Milano, Italy, July 21-26, 1996, Abstract CP016.

[14] W. Spevak, C. Foxall, D. H. Charych, F. Dasgupta, J. O. Nagy, J. Med. Chem. 1996, 39, 1018-1020.

[15] T. Murohara, J. Margiotta, L. M. Phillips, J. C. Paulson, S. DeFrees, S. Zalipsky, L. S. S. Guo, A. M. Lefer, Cardiovascular Res. 1995, 30, 965-974.

[16] S. A. DeFrees, L. Phillips, L. Guo, S. Zalipsky, J. Am. Chem. Soc. 1996, 118, $6101-6104$.

[17] G. Thoma, B. Ernst, F. Schwarzenbach, R. Duthaler, Bioorg. Med. Chem. Lett. 1997, 7, 1705-1708.

[18] V. Wittmann, S. Takayama, K. W. Gong, G. Weitz-Schmidt, C.-H. Wong, J. Org. Chem. 1998, 63, 5137-5143.

[19] For the application of a biotinylated $\mathrm{sLe}^{\mathrm{x}}$-BSA conjugate as reagent for staining activated endothelium cells see ref. [12].

[20] a) E. G. Weinhold, J. R. Knowles, J. Am. Chem. Soc. 1992, 114, 9270 9275; b) W. O. McClure, G. M. Edelman, Biochemistry 1966, 5, $1908-$ 1919.

[21] G. S. Jacob, C. Kirmaier, S. Z. Abbas, S. C. Howard, C. Steininger, J. K. Welply, P. Scudder, Biochemistry 1995, 34, 1210-1217.
[22] a) H. Kunz, Angew. Chem. 1987, 99, 297-311; Angew. Chem. Int. Ed. Engl. 1987, 26, 294-308; b) H. Paulsen, Angew. Chem. 1990, 102, 851-867; Angew. Chem. Int. Ed. Engl. 1990, 29, 823-838.

[23] For the synthesis of structurally related $O$-galactosides using different protecting group strategies than the ones presented in this publication see: a) S. Sabesan, J. Ø. Duus, S. Neira, P. Domaille, S. Kelm, J. C. Paulson, K. Bock, J. Am. Chem. Soc. 1992, 114, 8363-8375; b) N. M. Spijker, P. Westerduin, C. A. A. van Boeckel, Tetrahedron 1992, 48 6297-6316; c) D. M. Whitfield, H. Pang, J. P. Carver, J. Krepinsky, Can. J. Chem. 1990, 68, 942-952; d) Y. Ito, T. Ogawa, Agric. Biol. Chem. 1986, 50, 3231-3234; e) A. Maranduba, A. Veyrières, Carbohydr. Res. 1986, 151, $105-119$; f) K. Hotta, H. Ishida, M. Kiso, A Hasegawa, J. Carbohydr. Chem. 1994, 13, 175-192. See also ref. [6b].

[24] The regioselective alkylation at $3-\mathrm{OH}$ as well as the regioselective glycosylation at 6-OH of completely unprotected galactopyranosides via stannylene activation have been reported: a) J. Stanek, Jr., Topics Curr. Chem. 1990, 154, 209-256; b) P. J. Garegg, J.-L. Maloisel, S. Oscarson, Synthesis 1995, 409-414. However, attempts to apply these techniques to glycosylate the 6- and 3-position of $\mathbf{4}$ were unsuccessful.

[25] F. Micheel, A. Klemer, Adv. Carbohydr. Chem. 1961, 16, 85-103.

[26] G. Catelani, F. Colonna, A. Marra, Carbohydr. Res. 1988, 182, $297-$ 300.

[27] R. U. Lemieux, T. Takeda, B. Y. Chung, ACS Symp. Ser. 1976, 39, 90 115 .

[28] Ogawa et al. also observed a higher regioselectivity during the glycosylation of a $3^{\prime}, 4^{\prime}$-unprotected lactose derivative when the reaction was performed in nitromethane rather than in nonpolar solvents such as 1,2-dichloroethane or toluene: Y. Ito, S. Sato, M. Mori, T. Ogawa, J. Carbohydr. Chem. 1988, 7, 359-376.

[29] In $\mathrm{CDCl}_{3}$, the resonance of the proton geminal to the free hydroxyl group appeared at $3.36 \mathrm{ppm}$ as "ddd" $(J=3.1,7.1$, and $8.8 \mathrm{~Hz})$ and, after addition of $\mathrm{D}_{2} \mathrm{O}$, as "dd" $(J=7.1,8.8 \mathrm{~Hz})$ with coupling constants characteristic for 2-H of galactose. In addition, the multiplicity of the $\mathrm{OH}$ group resonance at $2.33 \mathrm{ppm}(\mathrm{d}, J=3.1 \mathrm{~Hz})$ was characteristic for a secondary rather than a primary alcohol.

[30] Early examples of the regioselective glycosylation at the 3-OH of 3,4deprotected galactopyranosides: a) H. Paulsen, M. Paal, D. Hadamczyk, K.-M. Steiger, Carbohydr. Res. 1984, 131, C1-C5. b) J. Alais, A. Veyrières, Tetrahedron Lett. 1983, 5223-5226.

[31] For the diglycosylation of a structurally related triol see ref. [23e].

[32] H. Ohle, W. Marecek, W. Bourjau, Chem. Ber. 1929, 62, 833-854.

[33] R. U. Lemieux, H. Driguez, J. Am. Chem. Soc. 1975, 97, 4069-4075.

[34] P. A. J. Gorin, Carbohydr. Res. 1982, 101, 13-20.

[35] S. K. Maity, S. K. Dutta, A. K. Banerjee, B. Achari, M. Singh, Tetrahedron 1994, 50, 6965-6974.

[36] O. Kanie, S. C. Crawley, M. M. Palcic, O. Hindsgaul, Carbohydr. Res. 1993, 243, 139-164.

[37] R. Knorr, A. Trzeciak, W. Bannwarth, D. Gillessen, Tetrahedron Lett. 1989, 30, 1927-1930.

[38] Recent reviews on enzymatic synthesis of carbohydrates: a) C.-H. Wong, R. L. Halcomb, Y. Ichikawa, T. Kajimoto, Angew. Chem. 1995, 107, 569-593; Angew. Chem. Int. Ed. Engl. 1995, 34, 521-546; b) H. J. M. Gijsen, L. Qiao, W. Fitz, C.-H. Wong, Chem. Rev. 1996, 96, $443-473$.

[39] C. Unverzagt, H. Kunz, J. C. Paulson, J. Am. Chem. Soc. 1990, 112, 9308-9309.

[40] In a model reaction, 15 was hydrogenated and coupled to Cbz-AspOMe under identical conditions as described for $\mathbf{1 6}$ to give the expected trisaccharide-aspartic acid conjugate in $68 \%$ yield. This conjugate can be used as a building block in solid-phase glycopeptide

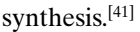

[41] O. Seitz, C.-H. Wong, J. Am. Chem. Soc. 1997, 119, 8766-8776.

[42] F. D. Tropper, F. O. Andersson, S. Braun, R. Roy, Synthesis 1992, 618 620.

[43] V. Wittmann, C.-H. Wong, J. Org. Chem. 1997, 62, 2144-2147.

[44] T. F. Tedder, C. M. Isaacs, T. J. Ernst, G. D. Demetri, D. A. Adler, C. M. Disteche, J. Exp. Med. 1989, 170, 123-133.

[45] M. P. Bevilaqua, S. Stengelin, M. A. Gimbrone Jr., B. Seed, Science 1989, 243, 1160-1165 